\title{
Article \\ The Theoretical Study of an Interconnected Suspension System for a Formula Student Car
}

\author{
Andrei-Cristian Pridie and Csaba Antonya *(D) \\ Department of Automotive and Transport Engineering, Transilvania University of Brasov, \\ RO-500036 Brasov, Romania; cristi_pridie@yahoo.com \\ * Correspondence: antonya@unitbv.ro; Tel.: +40-268-418-967
}

Citation: Pridie, A.-C.; Antonya, C. The Theoretical Study of an Interconnected Suspension System for a Formula Student Car. Appl. Sci. 2021, 11, 5507. https://doi.org/ 10.3390/app11125507

Academic Editor: Alessandro Gasparetto

Received: 10 May 2021

Accepted: 7 June 2021

Published: 14 June 2021

Publisher's Note: MDPI stays neutral with regard to jurisdictional claims in published maps and institutional affiliations.

Copyright: (c) 2021 by the authors. Licensee MDPI, Basel, Switzerland. This article is an open access article distributed under the terms and conditions of the Creative Commons Attribution (CC BY) license (https:// creativecommons.org/licenses/by/ $4.0 /)$.

\begin{abstract}
When it comes to racing applications, the primary engineering goal is to increase the performance envelope of the vehicle for a given set of tires. To achieve this goal, it is necessary to maximize the normal loads on the wheels while at the same time minimizing the tire load variation. The purpose of this paper is to present a mathematical model for a Formula Student car in order to study if performance gains are achieved by replacing the traditional passive suspension with a hydraulically interconnected suspension system. To have a complete picture of the advantages and disadvantages of each system, two vibrating models with 7 degrees of freedom were created in order to simulate the motion response of a Formula Student car to realistic excitations. Two particular interpretations of the results were chosen as important performance indicators. The first one is given by the pitch stability of the chassis relative to the road, which can be linked with a decrease in downforce load variation. The second one is the ability of the wheel to follow the road profile as closely as possible, which can be directly correlated with the amount of mechanical grip of the vehicle. The simulation results indicate that the hydraulically interconnected suspension system offers better results for both proposed cases but at the expense of the roll stability of the vehicle.
\end{abstract}

Keywords: hydraulic suspension; vibrating model; formula student; interconnected suspension

\section{Introduction}

The suspension system of a vehicle is represented by the totality of rigid and elastic links between the chassis of a vehicle and the wheels, which allows for the relative motion between the two. In commercial vehicle designs, the main goal of the suspension system is to provide to the driver and passengers of the vehicle as much comfort as possible. This is usually achieved by limiting the amplitude of vertical accelerations experienced by the human occupants. In racing applications, however, the role of the suspension is to increase the performance envelope of the vehicle in order to have better dynamic results. The performance envelope of the vehicle is essentially a graphical representation of the maximum achievable lateral and longitudinal accelerations for a given velocity. By studying the performance envelope of a racing car, we can see that the maximum lateral and braking acceleration achievable are a function of the sum of all tire friction ellipses, while the forward acceleration of the vehicle is engine-limited. Another conclusion we can draw from the performance envelope is the fact that an increase of velocity will also increase the maximum achievable lateral and braking accelerations. This is a result of the fact that additional normal loads are added to the tires by the downforce generated at the higher traveling velocity. Given the fact that any increase of the performance envelope translates directly to better dynamic performances, two targets are set for the design engineer of a race car.

The first target is the increase of the mechanical grip of the vehicle by improving the exploitation of the tire properties. The current engineering consensus when it comes to tire usage is that a minimization of the tire load variation [1] can be correlated with an overall increase in the grip provided. 
The second target of the design engineer must be the increase of the amount of downforce generated by the aerodynamic elements mounted on the vehicle. On a modern racing car, the majority of downforce $(60-70 \%)$ is generated by the underbody of the car because it is usually designed to function as a venturi tunnel. However, the downforce generated by flow of air under the body is very sensitive to changes of the pitch angle. Studies done on IndyCar vehicles demonstrated that up to $50 \%$ can be lost if the pitch of the car changes just $1.3^{\circ}$ [1]. Therefore, minimizing the pitch oscillation of the car is necessary to increase the aerodynamic grip.

The vibration behavior of the vehicle describes how the wheels of the vehicle (the unsprung mass) oscillate relative to the chassis of the vehicle (the sprung mass). When considering a conventional vehicle with four wheels, this relative oscillation of the unsprung mass can be categorized into four natural modes of vibration. The bounce mode occurs when all the wheels of the vehicle oscillate in phase. The roll mode occurs when the wheels on the same side are in phase while the ones on the opposite side are in counter phase. The pitch mode occurs when the wheels at one end are in phase and the ones at the opposite ends are in counter phase. Finally, twist or wrap mode occurs when the diagonally opposed wheels are in phase [2].

All other combinations of wheel displacement can be described by a combination of these 4 modes. By looking at Figure 1, we can also see that the only nonplanar mode of vibration is the wrap mode. This kind of wheel oscillation relative to the sprung mass can only be excited by the road surface; therefore, any kind of stiffening for this mode will only increase the load variance of the wheel [3], with detrimental effects on the overall mechanical grip of the vehicle.

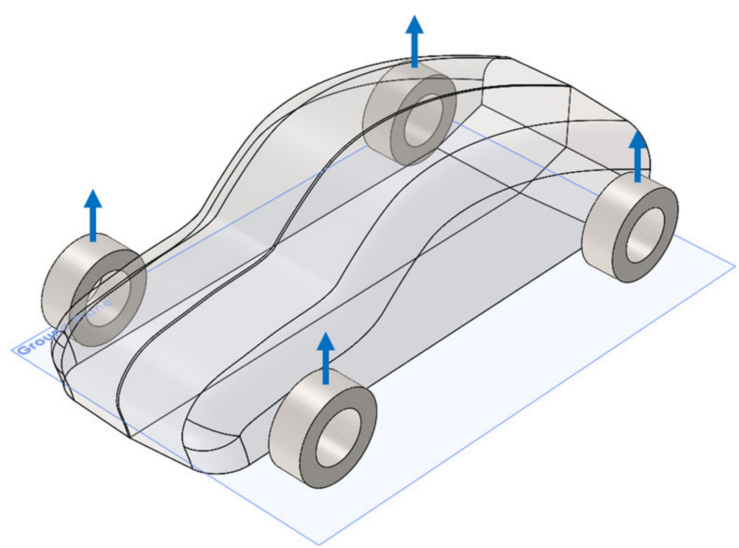

(a)

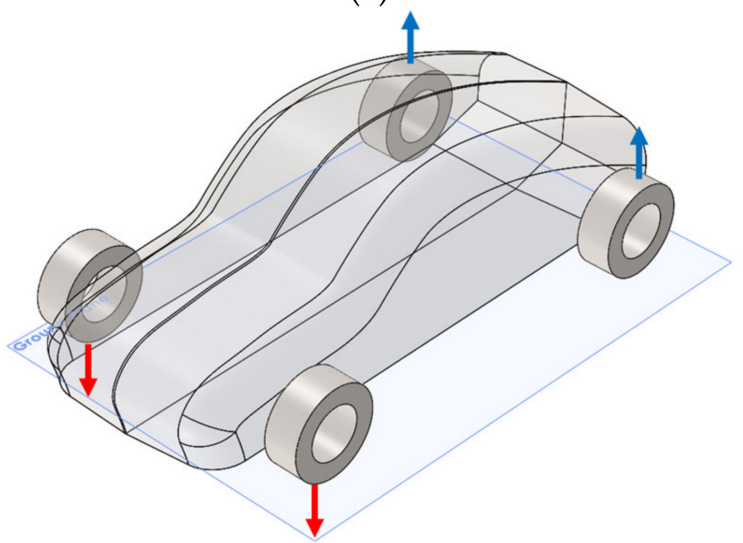

(c)

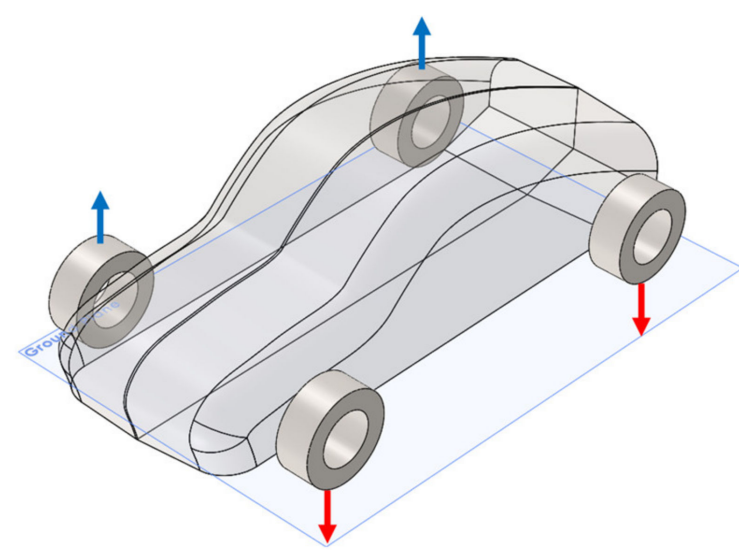

(b)

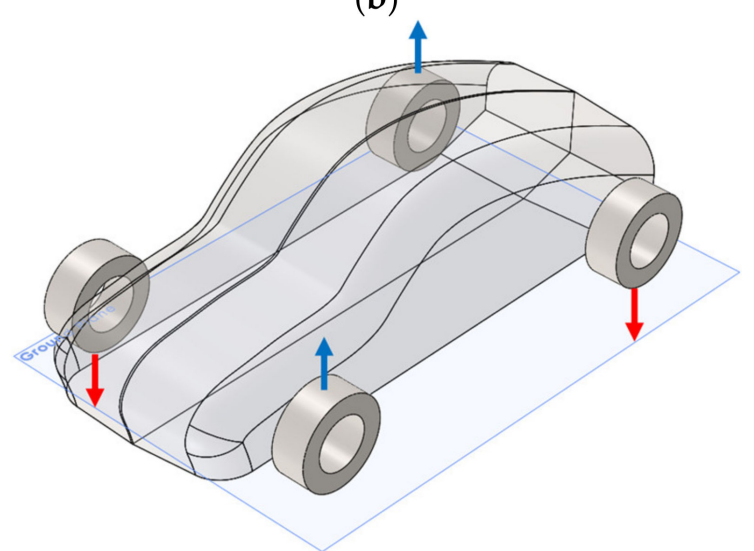

(d)

Figure 1. Modes of vibration. (a) Bounce, (b) roll, (c) pitch, and (d) wrap. 
The discussion about the natural modes of vibration allows us to distinguish some shortcomings of the conventional suspension system. By "conventional suspension system", we understand a suspension system in which each individual wheel is connected to the chassis with a combination of elastic and dissipation elements. This suspension layout creates a coupling of the natural modes of vibration because the same elastic and dissipation elements must deal with all possible oscillations of the wheels. As such, the natural frequencies of the system are a function of the stiffness of the springs, the distance from the center of gravity of the vehicle (CG) and the wheels, and the mass properties of the sprung mass. Naturally, the ability to choose each natural mode of vibration independently would significantly improve the performance of the suspension system by eliminating the necessity to compromise. Some improvements have been made, however, with the addition of the anti-roll bar (ARB). By interconnecting the wheels at the same end of the vehicle with another elastic element that will work in series with the wheel springs, the roll stiffness of the vehicle can be modified. The addition of this device, however, will inevitably increase the wrap stiffness of the vehicle. Another disadvantage of this system is the fact that, although radial dampers exist, they are usually not added in order to decrease the complexity and save weight. Therefore, although the roll stiffness of the vehicle is decoupled, the roll damping of the vehicle is still coupled because it is done by the wheel damper.

Another modification of the conventional suspension layout done to have more flexibility over the stiffnesses of the individual vibration modes is the addition of the third spring (also known as the heave spring). The purpose of this heave spring (which is paired with its own damper) is to decouple both the stiffness and dissipation of the bounce mode of vibration [4]. While this arrangement allows for the independent choice of stiffness for the bounce and roll modes of vibration, the pitch stiffness is coupled with the bounce modes because only the heave spring is deformed when either the bounce or pitch modes are excited. Another disadvantage of this arrangement is the fact that the roll and wrap modes of vibration are still coupled, therefore increasing the stiffness of the wrap mode of vibration.

These deficiencies of the traditional suspension layout created the necessity for alternative designs to solve the coupling problem. One possible solution to these challenges is the implementation of a hydraulically interconnected suspension system. Although not new, these solutions have not been explored to their full potential due to the overall higher level of complexity as well as higher expenses necessary for implementing and maintaining such a system. However, given the theoretical advantages that such a system can provide, a more in-depth analysis of such a system is required.

The implementation of hydraulic interconnected suspension systems for motorsport applications has been tried before with some promising results. A short review of literature on hydraulically interconnected suspension systems shows that the first one was proposed in 1927 [5] by J. B. Hawley. This patent application proposed the replacement of all dampers with double-acting cylinders that could be interconnected based on the sought-after effect. The proposals included schematics for four possible combinations of piston connections for anti-oppositional effects in roll, pitch, wrap, and a combination of roll and wrap.

Another important step in the evolution of hydraulically interconnected suspension systems was in 1979 [6], with a system implemented by the British Motor Corporation on Minis. This layout, proposed by Dr. Alex Moulton, consisted of hydraulically interconnected front-to-rear dampers. Through this system, the pitch stiffness of the vehicle could be independently controlled from the other modes, something he considered vital for improving the ride comfort.

More modern interpretations of hydraulic interconnected systems have been studied in recent times. A new such system is the $\mathrm{H} 2$, which was system patented by the Australian company Kinetic Pty Ltd. in 2003 [7]. This system uses two different hydraulic circuits to connect the different damper chambers of the 4 wheels. With this system, the damping for the pitch and bounce modes of vibration can be decoupled from the other modes. 
An evolution of this system was studied and patented by Trysome Ltd. and McLaren in 2009 [8]. This system had a similar functioning principle to the H2 system, but added 4 more hydraulic circuits in order to also control the pitch mode of the vehicle. Another improvement added by McLaren to this system was the addition of an active element to this suspension. First presented in 2017 on model 720S [9], the Proactive Chassis Control II uses needle valves and solenoids to manipulate the flow of the hydraulic liquid through the circuits in order to improve both the handling and the ride comfort of the vehicle.

A similar system has been used in Formula 1 in order to control the bounce and pitch of the car. These systems, however, lacked the active element implemented on the McLaren $720 \mathrm{~S}$ due to the FIA ban of active suspension in the competition. Although it showed some promising results, the system was banned in 2015 [10].

The model that is analyzed in this paper, first proposed by Smith and Walker in 2003 [2], seeks to completely decouple all modes of vibration by providing each of them with its own individual elastic and dissipation elements. In order for this complex separation to be possible, the proposed system replaces the elastic and dissipation elements that connect the sprung to the unsprung mass of the vehicle with a single acting piston. The purpose of this system is to convert relative displacement between the sprung and unsprung mass of the vehicle into flow in four different and independent hydraulic circuits. These circuits are connected to four different hydraulic cylinders, one single-acting cylinder and three other double-acting cylinders (Figure 2).

As it can be seen from the above picture, the cylinders are arranged in four different suspension units (one for each vibration mode). The task of this complex hydraulic circuit is to only create displacement in the suspension unit that is associated with a certain combination of wheel displacements. For example, if all wheels of the vehicle travel in the same direction with the same rate (bounce motion), then the only suspension unit that will register any displacement is the first one due to the fact that all forces push in the same direction. The units associated with the other modes will remain still for the reason that the double acting cylinders will have equal pressure on both sides.

The main goal of the present paper is to study the response of the hydraulically interconnected suspension system in order to find if substantial performance gains can be made by its adoption. In order to achieve this goal, two mathematical models will be constructed. One will be simulating the traditional suspension layout with front and rear ARBs, while the second model will simulate the hydraulic suspension system proposed by Smith and Walker. The mathematical vehicle models used for the simulations in this paper will be full car models. A full car model will give us a vibrating model with 7 degrees of freedom (DOF). This will allow us to independently monitor the motion of the 4 wheels as well as the bounce, roll, and pitch motions of the chassis.

Once the mathematical models are built, both will be applied to a vehicle with exactly the same dimensional and mass properties. The car chosen for this task is the Formula Student BS19 car built by Transilvania University of Brașov racing team BlueStreamline (Figure 3).

After the car parameters (all parameters are available in the Appendix A) have been introduced into the vehicle mathematical models that were created, two different simulations will be run. The first set of simulations will be run with a constant velocity where the only external excitation of the system is the road profile. In the second set of simulations, the lateral and longitudinal accelerations (obtained by running a lap time simulation software on a predetermined track) will also be considered, resulting in a set of data that can be better correlated with real-life vehicle performances. 


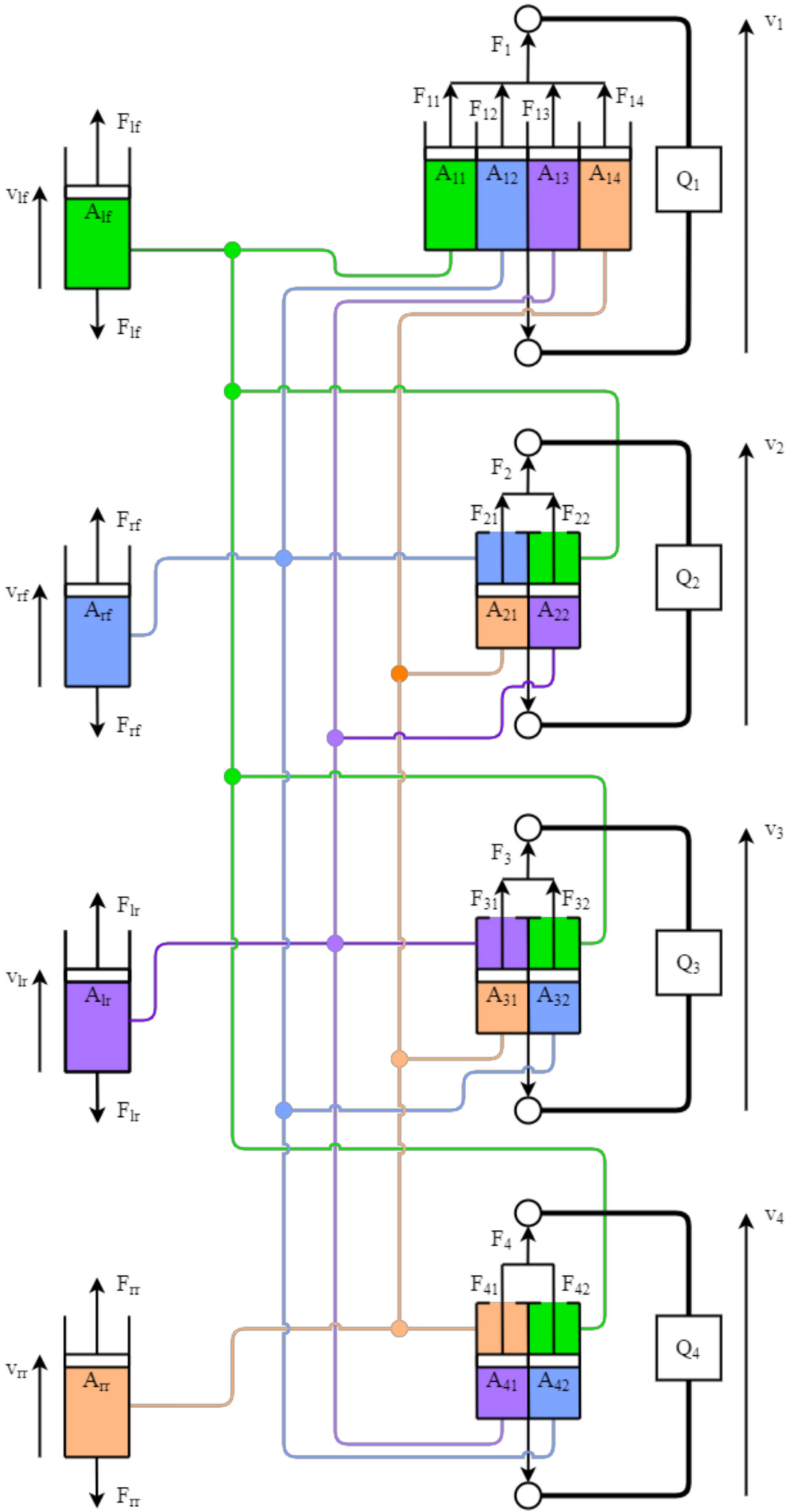

Figure 2. Hydraulically interconnected suspension system proposed by Smith and Walker (reproduced from [2]) A-area of piston, $\mathrm{F}$ - force at the piston, $\mathrm{v}$ - piston velocity, and Q - suspension unit admittance (defined by Equation (27)). 


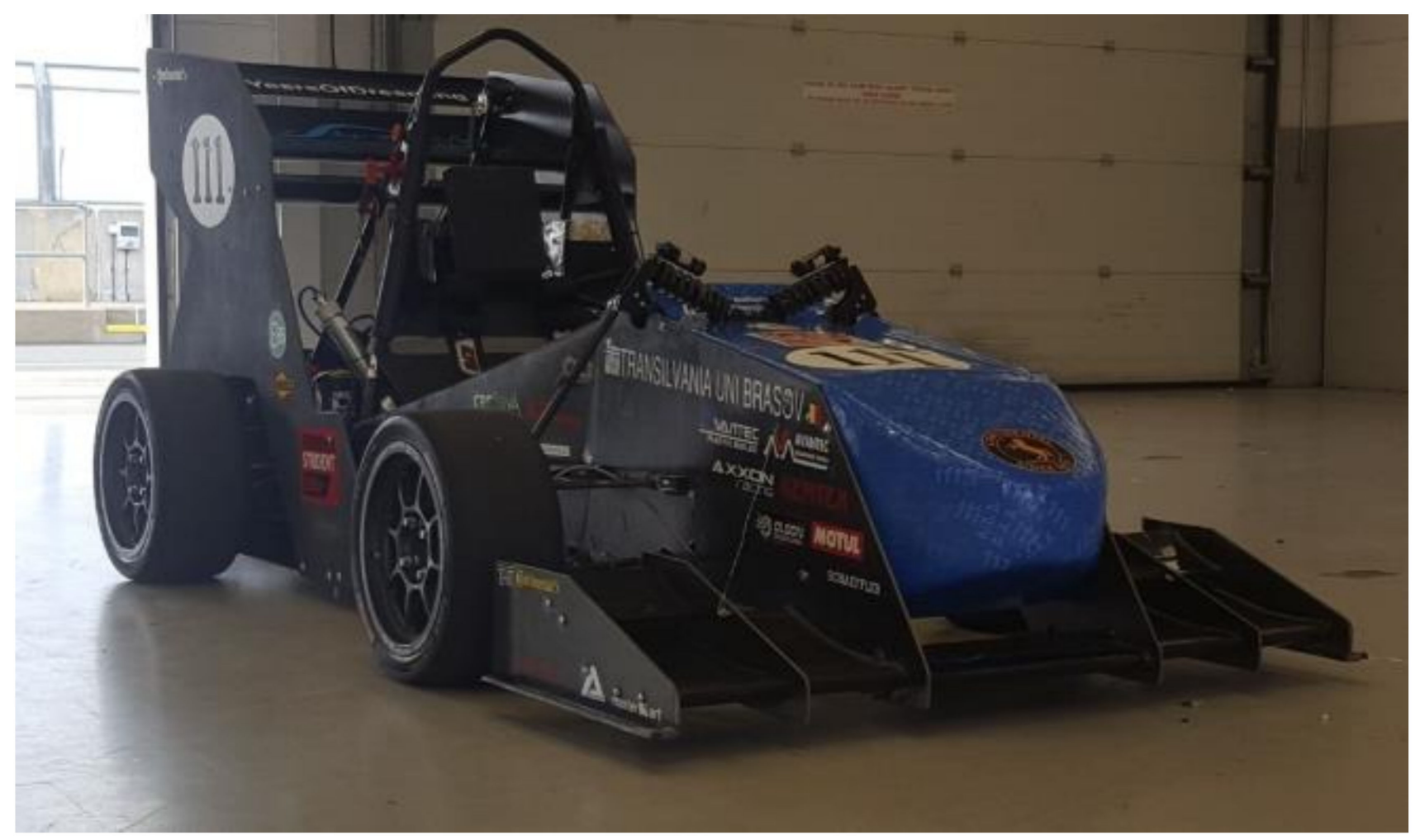

Figure 3. BlueStreamline BS19.

\section{Materials and Methods}

\subsection{Mathematical Modeling}

Before diving into the mathematical modelling for the two suspension systems, the notations used and the sign convention should be discussed. The traditional suspension model used for comparison is based on the work of professor Jazar [11]; therefore, the notations are as follows: body bounce $\mathrm{x}$; body roll $\rho$; body pitch $\theta$; wheels hop $\mathrm{x}_{1}, \mathrm{x}_{2}, \mathrm{x}_{3}$, and $x_{4}$; and road excitations for each wheel $y_{1}, y_{2}, y_{3}$, and $y_{4}$. For the sign convention, we will consider motions towards the ground negative for $x_{1} x_{1}, x_{2}, x_{3}$, and $x_{4}$. The values for $\mathrm{y}_{1}, \mathrm{y}_{2}, \mathrm{y}_{3}$, and $\mathrm{y}_{4}$ follow a similar rule, with the starting point being considered 0 and values above are positive. Body roll $\rho$ is considered positive when the chassis is rotating towards the right side, while $\theta$ is considered positive when the chassis is rotating towards the front.

One thing to note in the vehicle model proposed by Jazar is that the tires are modelled as simple springs. However, this simplification does not have a significant effect due to the small damping values of the tires.

Another problem that has to be solved is the use of the lateral and longitudinal accelerations of the vehicle as excitation for the vibrating vehicle model. For this, we need to calculate the moments of inertia for roll and pitch ( $\mathrm{I}_{\mathrm{r}}$ and $\mathrm{I}_{\mathrm{p}}$, respectively). The necessity for this step is given by the kinematic design of the suspension that imposes a given roll and pitch axis around which the sprung mass rotates. However, $\mathrm{I}_{\mathrm{r}}$ and $\mathrm{I}_{\mathrm{p}}$ can be calculated using the Huygens-Steiner theorem. Applied to the current problem, the equation takes the following form.

In order to introduce the effects of the lateral and longitudinal acceleration of the vehicle into the vibrating model, the pitch and roll moments of inertia were calculated with the following formula.

$$
\mathrm{I}=\mathrm{I}_{\mathrm{cm}}+\mathrm{m} \cdot \mathrm{d}^{2}
$$

I-resulting moment of inertia;

$\mathrm{I}_{\mathrm{cm}}$-inertia tensor ( $\mathrm{I}_{\mathrm{xx}}$ for roll and $\mathrm{I}_{\mathrm{yy}}$ for pitch); 
$\mathrm{d}$ - either the perpendicular distance between the CG and roll axis, or the perpendicular axis between the CG and the pitch axis.

Another aspect that needs to be introduced into the vibrating model is the effect of the longitudinal and lateral weight transfer. The method of calculation and the different components of this effect use the methodology presented by Rouelle [1].

The elastic weight transfer will take the following form:

$$
\begin{gathered}
\mathrm{R}_{\text {lat-wt }}=\mathrm{SM} \cdot \mathrm{a}_{\text {lat }} \cdot \Delta_{\mathrm{z}} \\
\mathrm{P}_{\text {long-wt }}=\mathrm{SM} \cdot \mathrm{a}_{\text {long }} \cdot \Delta_{\mathrm{PCZ}}
\end{gathered}
$$

where

SM-suspended mass [kg];

$\mathrm{a}_{\text {lat }}$-lateral acceleration $\left[\mathrm{m} / \mathrm{s}^{2}\right]$;

$\mathrm{a}_{\text {long }}$-longitudinal acceleration $\left[\mathrm{m} / \mathrm{s}^{2}\right]$;

$\Delta_{\mathrm{z}}$-distance from the CG of the suspended weight to the roll axis [m];

$\Delta_{\mathrm{PCz}}$-distance from the $C \mathrm{G}$ of the suspended weight to the pitch axis [m].

The geometric weight is calculated with

$$
\begin{gathered}
\mathrm{WT}_{\text {geo-f }}=\frac{\mathrm{SM} \cdot \frac{\mathrm{WD}_{\mathrm{SM}}}{100} \cdot \mathrm{a}_{\text {lat }} \cdot \mathrm{RC}_{\text {front }}}{\text { track }_{\text {front }}} \\
\mathrm{WT}_{\text {geo }-\mathrm{r}}=\frac{\mathrm{SM} \cdot \frac{100-\mathrm{WD}_{\mathrm{SM}}}{100} \cdot \mathrm{a}_{\text {lat }} \cdot \mathrm{RC}_{\text {rear }}}{\text { track }_{\text {rear }}} \\
\mathrm{WT}_{\text {geo-long }}=\frac{\mathrm{SM} \cdot \mathrm{a}_{\text {long }} \cdot \mathrm{PC}_{\mathrm{h}}}{\text { wheelbase }}
\end{gathered}
$$

where

$\mathrm{WD}_{\mathrm{SM}}$-weight distribution of the suspended mass [\%];

$\mathrm{PC}_{\mathrm{h}}$ - pitch center height [m];

$\mathrm{RC}_{\text {front/rear }}$-height of the front/rear roll center [m].

Finally, the non-suspended weight transfer is calculated with the following equations:

$$
\begin{gathered}
\mathrm{WT}_{\mathrm{NSW}-\mathrm{f}}=\frac{\mathrm{m}_{\mathrm{f}} \cdot 2 \cdot \mathrm{a}_{\text {lat }} \cdot \mathrm{h}_{\mathrm{NSM}-\mathrm{f}}}{\text { track }_{\text {front }}} \\
\mathrm{WT}_{\mathrm{NSW}-\mathrm{r}}=\frac{\mathrm{m}_{\mathrm{r}} \cdot 2 \cdot \mathrm{a}_{\text {lat }} \cdot \mathrm{h}_{\mathrm{NSM}-\mathrm{r}}}{\text { track }_{\text {rear }}} \\
\mathrm{WT}_{\mathrm{NSW}-\text { long }}=\frac{\left(\mathrm{m}_{\mathrm{f}}+\mathrm{m}_{\mathrm{r}}\right) \cdot 2 \cdot \mathrm{a}_{\text {long }} \cdot \mathrm{h}_{\mathrm{NSM}-\mathrm{t}}}{\text { Wheelbase }}
\end{gathered}
$$

where

$\mathrm{m}_{\mathrm{f}}$-Front unspung mass $[\mathrm{kg}]$;

$\mathrm{m}_{\mathrm{r}}$-Rear unspung mass [kg];

$\mathrm{h}_{\mathrm{NSM}-\mathrm{f}}$ - height of the front unspung mass CG $[\mathrm{m}]$;

$\mathrm{h}_{\mathrm{NSM}-\mathrm{r}}$ - height of the rear unspung mass CG $[\mathrm{m}]$;

$\mathrm{h}_{\mathrm{NSM}-\mathrm{t}}$ - height of the total unspung mass CG [m].

The last element needed for the dynamic simulations is the aerodynamic load generated by the vehicle. The equation for the total aerodynamic load generated is

$$
\mathrm{F}_{\mathrm{aero}-\mathrm{t}}=\frac{1}{2} \cdot \rho \cdot \mathrm{A}_{\mathrm{f}} \cdot \mathrm{C} \cdot \mathrm{v}^{2}
$$


where

$\rho$ - air density $=1230\left[\mathrm{~kg} / \mathrm{m}^{3}\right]$;

$\mathrm{A}_{\mathrm{f}}$-frontal area of the vehicle $=1.3\left[\mathrm{~m}^{2}\right]$;

C-downforce coefficient $=1.2[-]$;

$\mathrm{v}$-car velocity $[\mathrm{m} / \mathrm{s}]$.

\subsubsection{Traditional Passive Suspension Model}

For the traditional suspension layout, the suspension system was modelled having the BlueStreamline BS19 car as a reference where each wheel is connected to the chassis with a linear helicoidal spring paired with a hydraulic damper, plus front and rear ARBs. Some modifications are made to Jazar's model ([11] pp. 891-892) in order to accommodate the different front and rear track sizes of the BS19 as well as the inclusion of a rear ARB.

The equations of motion are obtained using a Lagrange equation for small and linear vibration. We obtain the following equation of motion:

$$
\begin{aligned}
& \mathrm{m} \ddot{x}+\left(2 \dot{\mathrm{x}}-\dot{\mathrm{x}}_{1}-\dot{\mathrm{x}}_{2}-2 \mathrm{a}_{1} \dot{\theta}\right) \mathrm{c}_{\mathrm{f}}+\left(2 \dot{\mathrm{x}}-\dot{\mathrm{x}}_{3}-\dot{\mathrm{x}}_{4}+2 \mathrm{a}_{2} \dot{\theta}\right) \mathrm{c}_{\mathrm{r}}+\left(2 \mathrm{x}-\mathrm{x}_{1}-\mathrm{x}_{2}-2 \mathrm{a}_{1} \theta\right) \mathrm{k}_{\mathrm{f}} \\
& +\left(2 \mathrm{x}-\mathrm{x}_{3}-\mathrm{x}_{4}-2 \mathrm{a}_{2} \theta\right) \mathrm{k}_{\mathrm{r}}=-\mathrm{F}_{\text {aero }-\mathrm{t}} \\
& \mathrm{I}_{\mathrm{x}} \ddot{\phi}+\left(2 \mathrm{~b}_{1} \dot{\phi}-\dot{\mathrm{x}}_{1}+\dot{\mathrm{x}}_{2}\right) \mathrm{b}_{1} \mathrm{c}_{\mathrm{f}}+\left(2 \mathrm{~b}_{2}{ }^{2} \dot{\phi}+\mathrm{b}_{2} \dot{\mathrm{x}}_{3}-\mathrm{b}_{2} \dot{\mathrm{x}}_{4}\right) \mathrm{b}_{2} \mathrm{c}_{\mathrm{r}}+\left(2 \mathrm{~b}_{1} \phi-\mathrm{x}_{1}+\mathrm{x}_{2}\right) \mathrm{b}_{1} \mathrm{k}_{\mathrm{f}} \\
& +\left(2 b_{2} \phi+x_{3}-x_{4}\right) b_{2} k_{r}+\frac{k_{R f}\left(x_{2}-x_{1}+2 b_{1} \phi\right)}{2 b_{1}} \\
& +\frac{\mathrm{k}_{\mathrm{Rr}}\left(\mathrm{x}_{3}-\mathrm{x}_{4}+2 \mathrm{~b}_{2} \phi\right)}{2 \mathrm{~b}_{2}}=\mathrm{R}_{\text {lat }-\mathrm{wt}} \\
& \mathrm{I}_{\mathrm{y}} \ddot{\theta}+\left(2 \mathrm{a}_{1} \dot{\theta}-2 \dot{\mathrm{x}}+\dot{\mathrm{x}}_{1}+\dot{\mathrm{x}}_{2}\right) \mathrm{a}_{1} \mathrm{c}_{\mathrm{f}}+\left(2 \mathrm{a}_{2} \dot{\theta}+2 \dot{\mathrm{x}}-\dot{\mathrm{x}}_{3}-\dot{\mathrm{x}}_{4}\right) \mathrm{a}_{2} \mathrm{c}_{\mathrm{r}} \\
& +\left(2 a_{1} \theta-2 x+x_{1}+x_{2}\right) a_{1} k_{f}+\left(2 a_{2} \theta+2 x-x_{3}-x_{4}\right) k_{r} \\
& =\mathrm{F}_{\text {aero }-\mathrm{f}} \cdot \mathrm{a}_{1}-\mathrm{F}_{\text {aero }-\mathrm{r}} \cdot \mathrm{a}_{2}-\mathrm{P}_{\text {long }-\mathrm{wt}} \\
& \mathrm{m}_{\mathrm{f}} \ddot{\mathrm{x}}_{1}+\left(\dot{\mathrm{x}}_{1}-\dot{\mathrm{x}}-\mathrm{b}_{1} \dot{\phi}+\mathrm{a}_{1} \dot{\theta}\right) \mathrm{c}_{\mathrm{f}}+\left(\mathrm{x}_{1}-\mathrm{x}-\mathrm{b}_{1} \phi+\mathrm{a}_{1} \theta\right) \mathrm{k}_{\mathrm{f}}-\left(\frac{\mathrm{x}_{2}-\mathrm{x}_{1}+2 \mathrm{~b}_{1} \phi}{\mathrm{b}_{1}{ }^{2} 4}\right) \mathrm{k}_{\mathrm{Rf}} \\
& +\mathrm{k}_{\mathrm{tf}}\left(\mathrm{x}_{1}-\mathrm{y}_{1}\right)=-\mathrm{WT}_{\text {geo }-\mathrm{f}}-\mathrm{WT}_{\mathrm{nsm}-\mathrm{f}}+\frac{\mathrm{WT}_{\text {geo }- \text { long }}}{2}+\frac{\mathrm{WT}_{\mathrm{nsm}-\text { long }}}{2} \\
& \mathrm{~m}_{\mathrm{f}} \ddot{\mathrm{x}}_{2}+\left(\dot{\mathrm{x}}_{2}-\dot{\mathrm{x}}+\mathrm{b}_{1} \dot{\phi}+\mathrm{a}_{1} \dot{\theta}\right) \mathrm{c}_{\mathrm{f}}+\left(\mathrm{x}_{2}-\mathrm{x}+\mathrm{b}_{1} \phi+\mathrm{a}_{1} \theta\right) \mathrm{k}_{\mathrm{f}}+\left(\frac{\mathrm{x}_{2}-\mathrm{x}_{1}+2 \mathrm{~b}_{1} \phi}{\mathrm{b}_{1}{ }^{2} 4}\right) \mathrm{k}_{\mathrm{Rf}} \\
& +\mathrm{k}_{\mathrm{tf}}\left(\mathrm{x}_{2}-\mathrm{y}_{2}\right)=\mathrm{WT}_{\text {geo }-\mathrm{f}}+\mathrm{WT}_{\mathrm{nsm}-\mathrm{f}}+\frac{\mathrm{WT}_{\text {geo-long }}}{2}+\frac{\mathrm{WT}_{\mathrm{nsm}-\text { long }}}{2} \\
& \mathrm{~m}_{\mathrm{f}} \ddot{\mathrm{x}}_{3}+\left(\dot{\mathrm{x}}_{3}-\dot{\mathrm{x}}+\mathrm{b}_{2} \dot{\phi}-\mathrm{a}_{2} \dot{\theta}\right) \mathrm{c}_{\mathrm{r}}+\left(\mathrm{x}_{3}-\mathrm{x}+\mathrm{b}_{2} \phi-\mathrm{a}_{2} \theta\right) \mathrm{k}_{\mathrm{r}}+\left(\frac{\mathrm{x}_{3}-\mathrm{x}_{4}+2 \mathrm{~b}_{2} \phi}{\mathrm{b}_{1}{ }^{2} 4}\right) \mathrm{k}_{\mathrm{Rr}} \\
& +\mathrm{k}_{\mathrm{tf}}\left(\mathrm{x}_{3}-\mathrm{y}_{3}\right)=\mathrm{WT}_{\text {geo }-\mathrm{r}}+\mathrm{WT}_{\mathrm{nsm}-\mathrm{r}}-\frac{\mathrm{WT}_{\text {geo-long }}}{2}-\frac{\mathrm{WT}_{\mathrm{nsm}-\text { long }}}{2} \\
& \mathrm{~m}_{\mathrm{f}} \ddot{\mathrm{x}}_{4}+\left(\dot{\mathrm{x}}_{4}-\dot{\mathrm{x}}-\mathrm{b}_{2} \dot{\phi}-\mathrm{a}_{2} \dot{\theta}\right) \mathrm{c}_{\mathrm{r}}+\left(\mathrm{x}_{4}-\mathrm{x}-\mathrm{b}_{2} \phi-\mathrm{a}_{2} \theta\right) \mathrm{k}_{\mathrm{r}}-\left(\frac{\mathrm{x}_{3}-\mathrm{x}_{4}+2 \mathrm{~b}_{2} \phi}{\mathrm{b}_{1}{ }^{2} 4}\right) \mathrm{k}_{\mathrm{Rr}} \\
& +\mathrm{k}_{\mathrm{tf}}\left(\mathrm{x}_{4}-\mathrm{y}_{4}\right)=-\mathrm{WT}_{\text {geo }-\mathrm{r}}-\mathrm{WT}_{\mathrm{nsm}-\mathrm{r}}-\frac{\mathrm{WT}_{\text {geo }- \text { long }}}{2}-\frac{\mathrm{WT}_{\mathrm{nsm}-\text { long }}}{2} \\
& \text { where } \\
& \mathrm{m} \text {-sprung mass; } \\
& \mathrm{m}_{1} \& \mathrm{~m}_{2} \text {-front wheel mass; } \\
& \mathrm{m}_{3} \& \mathrm{~m}_{4} \text {-rear wheel mass; } \\
& \mathrm{I}_{\mathrm{r}}-\text { roll moment of inertia; } \\
& \mathrm{I}_{\mathrm{p}} \text { - pitch moment of inertia; } \\
& \mathrm{a}_{1} \text {-longitudinal distance from the front wheels to the pitch center; }
\end{aligned}
$$


$\mathrm{a}_{2}$-longitudinal distance from the rear wheels to the pitch center;

$\mathrm{b}_{1}$-lateral distance from the front wheels to the roll center;

$\mathrm{a}_{2}$-lateral distance from the rear wheels to the roll center;

$\mathrm{k}_{\mathrm{f}}$-stiffness of the front springs;

$\mathrm{k}_{\mathrm{r}}$-stiffness of the rear springs;

$\mathrm{k}_{\mathrm{tf}}$-stiffness of the front tires;

$\mathrm{k}_{\mathrm{tr}}$-stiffness of the rear tires;

$\mathrm{k}_{\mathrm{Rf}}$-stiffness of the rear ARB;

$\mathrm{k}_{\mathrm{Rr}}$-stiffness of the rear ARB;

$\mathrm{F}_{\text {aero-t }}$ - total aerodynamic downforce;

$\mathrm{F}_{\text {aero-f }}-\mathrm{F}_{\text {aero-t }}{ }^{*}$ downforce distribution;

$\mathrm{F}_{\text {aero-fr }}-\mathrm{F}_{\text {aero-t }}{ }^{*}$ (1-downforce distribution);

$\mathrm{R}_{\text {lat-wt }}$-roll moment caused by weight transfer;

$\mathrm{R}_{\text {long-wt }}$ - pitch moment caused by weight transfer.

\subsubsection{Hydraulically Interconnected Suspension Model}

For this model, the equations of motion are derived using the Newton method. This method is necessary since the relative forces between the sprung and unsprung mass are functions of the relative motions of the unsprung masses relative to the sprung mass. By reducing the total force given by the system at each wheel with $\mathrm{F}_{\mathrm{lf}}, \mathrm{F}_{\mathrm{rf}}, \mathrm{F}_{\mathrm{lr}}$, and $\mathrm{F}_{\mathrm{rr}}$, we obtain the following equations:

$$
\begin{aligned}
& m \ddot{x}=-F_{\text {aero- } t}-\left(\frac{F_{l f}+F_{l r}}{{M R_{f}}_{f}}+\frac{F_{r f}+F_{r r}}{M R_{r}}\right) \\
& \mathrm{I}_{\mathrm{r}} \ddot{\phi}=\mathrm{R}_{\text {lat }-\mathrm{wt}}-\left(\mathrm{b}_{1}\left(\frac{\mathrm{F}_{\mathrm{rf}}}{\mathrm{MR}_{\mathrm{f}}}-\frac{\mathrm{F}_{\mathrm{lf}}}{\mathrm{MR}_{\mathrm{f}}}\right)+\mathrm{b}_{2}\left(-\frac{\mathrm{F}_{\mathrm{lr}}}{\mathrm{MR}_{\mathrm{r}}}+\frac{\mathrm{F}_{\mathrm{rr}}}{\mathrm{MR}_{\mathrm{r}}}\right)\right) \\
& \mathrm{I}_{\mathrm{p}} \ddot{\theta}=\mathrm{F}_{\text {aero-f }} \cdot \mathrm{a}_{1}-\mathrm{F}_{\text {aero- }-\mathrm{r}} \cdot \mathrm{a}_{2}-\mathrm{P}_{\text {long }-\mathrm{wt}}-\left(-\frac{\mathrm{a}_{1}}{\mathrm{MR}_{\mathrm{f}}}\left(\mathrm{F}_{\mathrm{rf}}+\mathrm{F}_{\mathrm{lf}}\right)+\frac{\mathrm{a}_{2}}{\mathrm{MR}_{\mathrm{r}}}\left(\mathrm{F}_{\mathrm{rr}}+\mathrm{F}_{\mathrm{lr}}\right)\right) \\
& \mathrm{m}_{1} \ddot{\mathrm{x}}_{1}=-\mathrm{WT}_{\text {geo-f-lat }}-\mathrm{WT}_{\mathrm{nsm}-\mathrm{f}-\text { lat }}+\frac{\mathrm{WT}_{\text {geo-f-long }}}{2}+\frac{\mathrm{WT}_{\mathrm{nsm}-\mathrm{f}-\text { long }}}{2}+\frac{\mathrm{F}_{\text {lf }}}{\mathrm{MR}_{\mathrm{f}}} \\
& -\mathrm{k}_{\mathrm{tf}}\left(\mathrm{x}_{1}-\mathrm{y}_{1}\right) \\
& \mathrm{m}_{2} \ddot{\mathrm{x}}_{2}=\mathrm{WT}_{\text {geo-f-lat }}+\mathrm{WT}_{\mathrm{nsm}-\mathrm{f}-\mathrm{lat}}+\frac{\mathrm{WT}_{\text {geo }-\mathrm{f}-\text { long }}}{2}+\frac{\mathrm{WT}_{\mathrm{nsm}-\mathrm{f}-\text { long }}}{2}+\frac{\mathrm{F}_{\mathrm{rf}}}{\mathrm{MR}_{\mathrm{f}}} \\
& -\mathrm{k}_{\mathrm{tf}}\left(\mathrm{x}_{2}-\mathrm{y}_{2}\right) \\
& \mathrm{m}_{3} \ddot{\mathrm{x}}_{3}=\mathrm{WT}_{\text {geo-f-lat }}+\mathrm{WT}_{\mathrm{nsm}-\mathrm{f}-\mathrm{lat}}-\frac{\mathrm{WT}_{\text {geo }-\mathrm{f}-\text { long }}}{2}-\frac{\mathrm{WT}_{\mathrm{nsm}-\mathrm{f}-\text { long }}}{2}+\frac{\mathrm{F}_{\mathrm{rr}}}{\mathrm{MR}_{\mathrm{r}}} \\
& -\mathrm{k}_{\mathrm{tr}}\left(\mathrm{x}_{3}-\mathrm{y}_{3}\right) \\
& \mathrm{m}_{4} \ddot{\mathrm{x}}_{4}=-\mathrm{WT}_{\text {geo-f-lat }}-\mathrm{WT}_{\mathrm{nsm}-\mathrm{f}-\mathrm{lat}}-\frac{\mathrm{WT}_{\text {geo-f-long }}}{2}-\frac{\mathrm{WT}_{\mathrm{nsm}-\mathrm{f}-\text { long }}}{2}+\frac{\mathrm{F}_{\text {lr }}}{\mathrm{MR}_{\mathrm{r}}} \\
& -\mathrm{k}_{\operatorname{tr}}\left(\mathrm{x}_{4}-\mathrm{y}_{4}\right)
\end{aligned}
$$

where

$\mathrm{F}_{\mathrm{lf}}$-relative force between the front left unsprung mass and sprung mass;

$\mathrm{F}_{\mathrm{rf}}$-relative force between the front right unsprung mass and sprung mass;

$\mathrm{F}_{\mathrm{rr}}$-relative force between the rear right unsprung mass and sprung mass;

$\mathrm{F}_{\mathrm{rl}}$-relative force between the rear left unsprung mass and sprung mass;

$\mathrm{MR}_{\mathrm{f}}$ - wheel leverage ratio front (wheel motion/cylinder motion);

$\mathrm{MRr}$ - wheel leverage ratio rear (wheel motion/cylinder motion).

$\mathrm{F}_{\mathrm{lf}}, \mathrm{F}_{\mathrm{rf}}, \mathrm{F}_{\mathrm{lr}}$, and $\mathrm{F}_{\mathrm{rr}}$ are calculated using the relative motions of the wheels to the chassis. 
These are calculated using the mathematical model provided by Smith and Walker [2]. Therefore, the values of the mentioned forces are calculated using the inverse Laplace of the following equations [2]

$$
\left[\begin{array}{c}
\hat{\mathrm{F}}_{\mathrm{lf}} \\
\hat{\mathrm{F}}_{\mathrm{rf}} \\
\hat{\mathrm{F}}_{\mathrm{lr}} \\
\hat{\mathrm{F}}_{\mathrm{rr}}
\end{array}\right]=\left(\mathrm{T}^{\prime}\right)^{-1} \cdot \operatorname{diag}\left(\mathrm{Q}_{1} \mathrm{Q}_{2} \mathrm{Q}_{3} \mathrm{Q}_{4}\right) \cdot \mathrm{T}^{-1} \cdot\left[\begin{array}{c}
\hat{\mathrm{v}}_{\mathrm{lf}} \\
\hat{\mathrm{V}}_{\mathrm{rf}} \\
\hat{\mathrm{v}}_{\mathrm{lr}} \\
\hat{\mathrm{v}}_{\mathrm{rr}}
\end{array}\right]
$$

and

$$
\begin{gathered}
\mathrm{T}=\left[\begin{array}{cccc}
-\frac{\mathrm{A}_{11}}{\mathrm{~A}_{\mathrm{lf}}} & \frac{\mathrm{A}_{22}}{\mathrm{~A}_{\mathrm{lf}}} & \frac{\mathrm{A}_{32}}{\mathrm{~A}_{\mathrm{lf}}} & \frac{\mathrm{A}_{42}}{\mathrm{~A}_{\mathrm{lf}}} \\
-\frac{\mathrm{A}_{12}}{\mathrm{~A}_{\mathrm{rf}}} & \frac{\mathrm{A}_{21}}{\mathrm{~A}_{\mathrm{rf}}} & -\frac{\mathrm{A}_{32}}{\mathrm{~A}_{\mathrm{rf}}} & -\frac{\mathrm{A}_{42}}{\mathrm{~A}_{\mathrm{rf}}} \\
-\frac{\mathrm{A}_{13}}{\mathrm{~A}_{\mathrm{lr}}} & -\frac{\mathrm{A}_{22}}{\mathrm{~A}_{\mathrm{lr}}} & \frac{\mathrm{A}_{31}}{\mathrm{~A}_{\mathrm{lr}}} & -\frac{\mathrm{A}_{41}}{\mathrm{~A}_{\mathrm{lr}}} \\
-\frac{\mathrm{A}_{14}}{\mathrm{~A}_{\mathrm{rr}}} & -\frac{\mathrm{A}_{21}}{\mathrm{~A}_{\mathrm{rr}}} & -\frac{\mathrm{A}_{31}}{\mathrm{~A}_{\mathrm{rr}}} & \frac{\mathrm{A}_{41}}{\mathrm{~A}_{\mathrm{rr}}}
\end{array}\right] \\
\mathrm{Q}_{\mathrm{x}}=\frac{\mathrm{k}_{\mathrm{x}}}{\mathrm{s}}+\mathrm{c}_{\mathrm{x}} \\
{\left[\begin{array}{c}
\mathrm{v}_{\mathrm{lf}} \\
\mathrm{v}_{\mathrm{rf}} \\
\mathrm{v}_{\mathrm{lr}} \\
\mathrm{v}_{\mathrm{rr}}
\end{array}\right]=\left[\begin{array}{c}
\frac{\dot{\mathrm{x}}-\dot{x_{1}}+\mathrm{b}_{1} \dot{\phi}-\mathrm{a}_{1} \dot{\theta}}{\mathrm{MR}_{\mathrm{f}}} \\
\frac{\dot{\mathrm{x}}-\dot{\mathrm{x}_{2}}-\mathrm{b}_{1} \dot{\phi}-\mathrm{a}_{1} \dot{\theta}}{\mathrm{MR}_{\mathrm{f}}} \\
\frac{\dot{\mathrm{x}}-\dot{x_{4}}+\mathrm{b}_{2} \dot{\phi}+\mathrm{a}_{2} \dot{\theta}}{\mathrm{MR}_{\mathrm{r}}} \\
\frac{\dot{\mathrm{x}}-\dot{\mathrm{x}_{3}}-\mathrm{b}_{2} \dot{\phi}+\mathrm{a}_{2} \dot{\theta}}{\mathrm{MR}_{\mathrm{r}}}
\end{array}\right]}
\end{gathered}
$$

where

$\mathrm{A}_{\mathrm{xx}}$-area of cylinder xx (Figure 2);

$\mathrm{A}_{\mathrm{lf}}$ - area of the front left wheel cylinder;

$\mathrm{A}_{\mathrm{rf}}$ - area of the front right wheel cylinder;

$\mathrm{A}_{\mathrm{rr}}$ - area of the rear right wheel cylinder;

$\mathrm{A}_{\mathrm{lr}}$ - area of the rear left wheel cylinder;

$\mathrm{v}_{\mathrm{lf}}$-relative velocity between the front left wheel and the chassis;

$\mathrm{v}_{\mathrm{rf}}$-relative velocity between the front right wheel and the chassis;

$\mathrm{v}_{\mathrm{rr}}$-relative velocity between the rear right wheel and the chassis;

$\mathrm{v}_{\mathrm{rl}}$-relative velocity between the rear left wheel and the chassis;

$\mathrm{k}$-spring stiffness;

$\mathrm{c}$-damping rate.

The $\mathrm{x}$ in Equation (27) represents a number from 1 to $4 ; 1$ is attributed to the bounce suspension unit, 2 is attributed to the pitch suspension unit, 3 is attributed to the roll suspension unit, and 4 to the wrap suspension unit.

\subsubsection{Damper Modelling}

Although previously the damping rate was described as a linear function of the compression/extension velocity, most automotive dampers are modified to have different damping rates based on both the direction and value of the damper's compression/extension velocity.

The asymmetry of the damper when it comes to the compression vs. the extension motion is a deliberate design choice. The necessity of this design is described by Giariffa and Brisson [12], by pointing out that at compression the energy of the system is stored in the spring. This means that less damping is required at this point as opposed to the rebound 
motion of the suspension when the energy released by the spring has to be dissipated in order to avoid excessive oscillations of the wheel. Usually, this asymmetry means that the rebound damping rate is between 2 and 4 times higher [12-15] than the damping rate during compression.

On top of the asymmetry discussed previously, there is another departure from the linear model given by the internal architecture of the damper. Although there are pressure valves on the piston of the damper, they usually do not open until a certain velocity is reached (also known as the knee velocity). Before this point, the hydraulic liquid inside the damper will flow around the piston resulting in a higher damping rate. Once the knee velocity is reached, the pressure valves open, allowing more flow inside the damper leading to a reduction of the damping rate. Usually, however, this is a useful characteristic because the lower velocity damping rate can be used to control the motion of the car, while the lower damping rate, which happens at higher damper velocity, is used to control the motion of the wheel over road irregularities.

The value of the damping rate as a function damper velocity can be calculated using the following formula:

$$
F_{C}= \begin{cases}C_{D} \cdot\left(1-e_{D}\right) \cdot v^{\lambda} & 0<v<1 \\ C_{D} \cdot\left(1-e_{D}\right) \cdot\left[1^{\lambda} \cdot\left(1-\frac{1}{r}\right)+\frac{v^{\lambda}}{r}\right] & v>1 \\ C_{D} \cdot\left(1-e_{D}\right)^{-1} \cdot\left(-v^{\lambda}\right) & -1<v<0 \\ C_{D} \cdot\left(1-e_{D}\right)^{-1} \cdot\left[1^{\lambda} \cdot\left(1-\frac{1}{r}\right)+\frac{-v^{\lambda}}{r}\right] & v<-1\end{cases}
$$

and

$$
\mathrm{C}_{\mathrm{D}}=\xi \cdot 2 \cdot \sqrt{\mathrm{K} \cdot \mathrm{m}}
$$

where

$\mathrm{F}_{\mathrm{C}}$-damping force;

$\mathrm{C}_{\mathrm{D}}$-damping rate;

$\mathrm{e}_{\mathrm{D}}$-asymmetry factor (desired ratio between the compression and rebound forces);

$\lambda$-progressive factor ( 0 for Coulomb friction, 1 for viscous friction 2 for quadratic damping);

l-knee velocity;

$\mathrm{r}$-desired ratio between low and high velocity damping;

$\mathrm{v}$-damper piston velocity (positive for compression and negative for rebound);

$\xi$-damping ratio;

$\mathrm{K}$-the spring rate from which the energy is dissipated;

$\mathrm{m}$-sprung mass acting on the damper.

The dampers where there is a compressive/rebound asymmetry will be used for all dampers present on the traditional suspension layout. However, on the hydraulic interconnected suspension layout, only the bounce suspension unit will have a damper with asymmetry to avoid roll and pitch inconsistencies. The force-velocity graphs for all the dampers in the models are shown in Appendix B.

\subsubsection{Simulation Method and Software Tools}

In order to solve the two systems of seven ordinary differential equations (ODEs) created for the two vibrating systems, the ode 45 solver from MATLAB ${ }^{\circledR}$ was used [16]. As such, two separate functions were created in which the ODEs for each system were written as state-space models. Before the state-space model, however, a simple if/else statement is used to select the correct damping rate for each damper based on Equation (29). For the traditional suspension layout, to determine the damper velocity at each wheel, Equation (28) will be used. When it comes to the hydraulic interconnected suspension, 
however, we need to use the following equation [2] to correctly calculate the velocities of each suspension unit:

$$
\left[\begin{array}{c}
\mathrm{v}_{1} \\
\mathrm{v}_{2} \\
\mathrm{v}_{3} \\
\mathrm{v}_{4}
\end{array}\right]=\mathrm{T}^{-1} \cdot\left[\begin{array}{c}
\mathrm{v}_{\mathrm{lf}} \\
\mathrm{v}_{\mathrm{rf}} \\
\mathrm{v}_{\mathrm{lr}} \\
\mathrm{v}_{\mathrm{rr}}
\end{array}\right]
$$

Another software program used to simulate the vibrating response of the vehicle is OptimumLap ${ }^{\circledR}$ [17]. The purpose of this program is to calculate the lateral and longitudinal accelerations as well as the velocity of the simulated vehicle along a given track. The software completes this task by using a quasi-steady-state simulation model that reduces the vehicle to a single mass point [17]. In order for this model to be able to approximate the velocity of the vehicle along the given track, the performance envelope of the vehicle is used (Figure 4). The performance envelope of the vehicle is created by stacking on top of each other the friction ellipses of the vehicle at different velocities and then combining them with the traction model of the car.

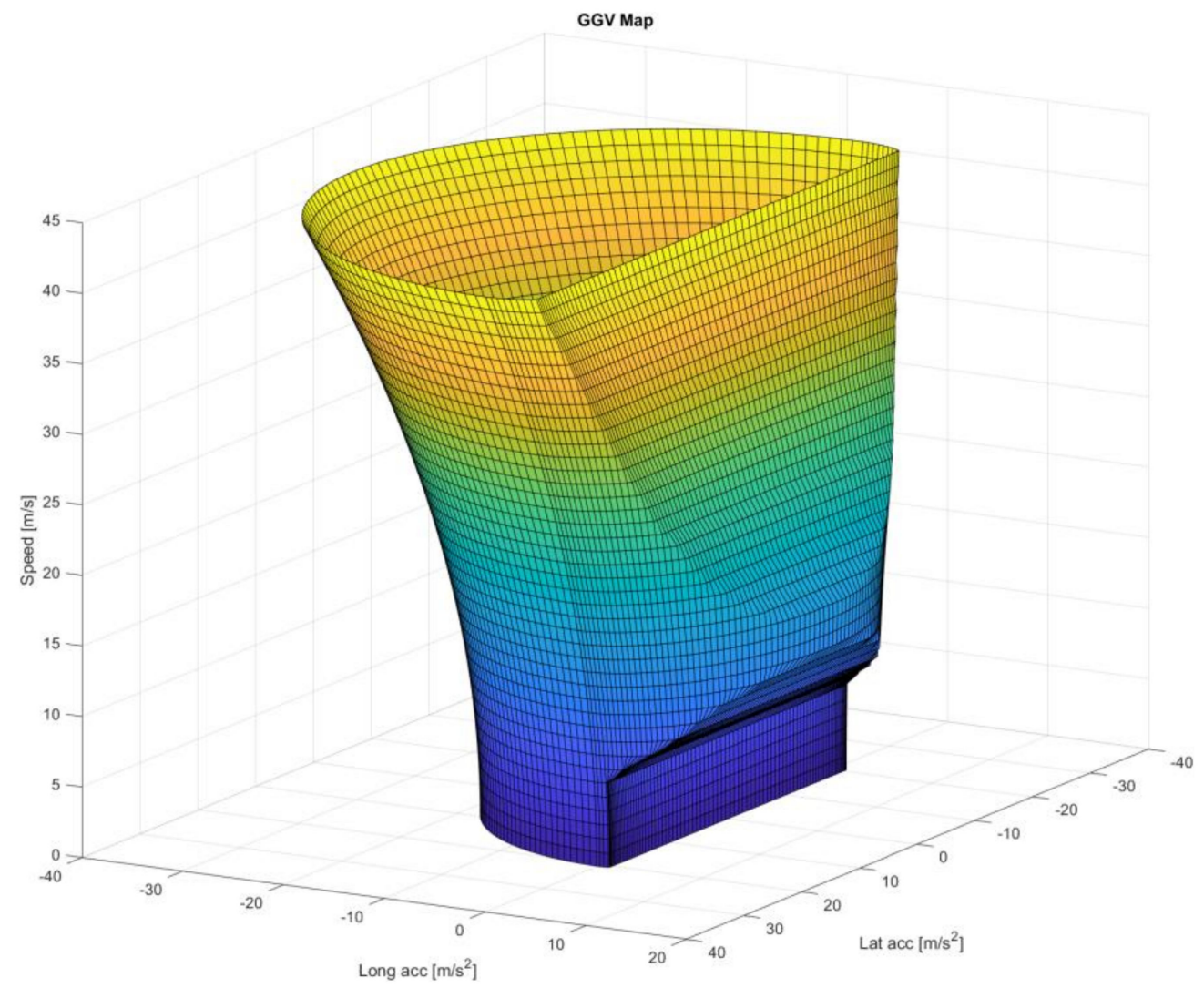

Figure 4. Performance envelope of the BS19 Formula Student car.

Although more complex lap time simulation methods are available, the complexity of these methods and the large number of variables that must be taken into account can lead to extremely long computation times [18] for a personal computer; therefore, they were deemed unsuitable for the current simulation. Moreover, the correlation of the quasisteady-state simulation method with more complex simulation methods, as well as with real-life data, reveals that the results have negligible differences (under 1\%).

The track used in this simulation was created to be both simple to compute and a realistic representation for a part of a Formula Student Track. Using these two principles, the chosen track has the following configuration (Figure 5): the start line is followed by a $60 \mathrm{~m}$ straight, at the end of which there is a corner with a radius of $20 \mathrm{~m}$ and length of $70 \mathrm{~m}$. At the end of the first corner, a right-hand corner with a radius of $9 \mathrm{~m}$ (the minimum corner 
radius allowed by the FSAE rules) and a length of $31.5 \mathrm{~m}$ will follow. After a straight of $20 \mathrm{~m}$, there is a portion of the track for slalom manoeuvres that leads into the final $30 \mathrm{~m}$ straight to the finish line.

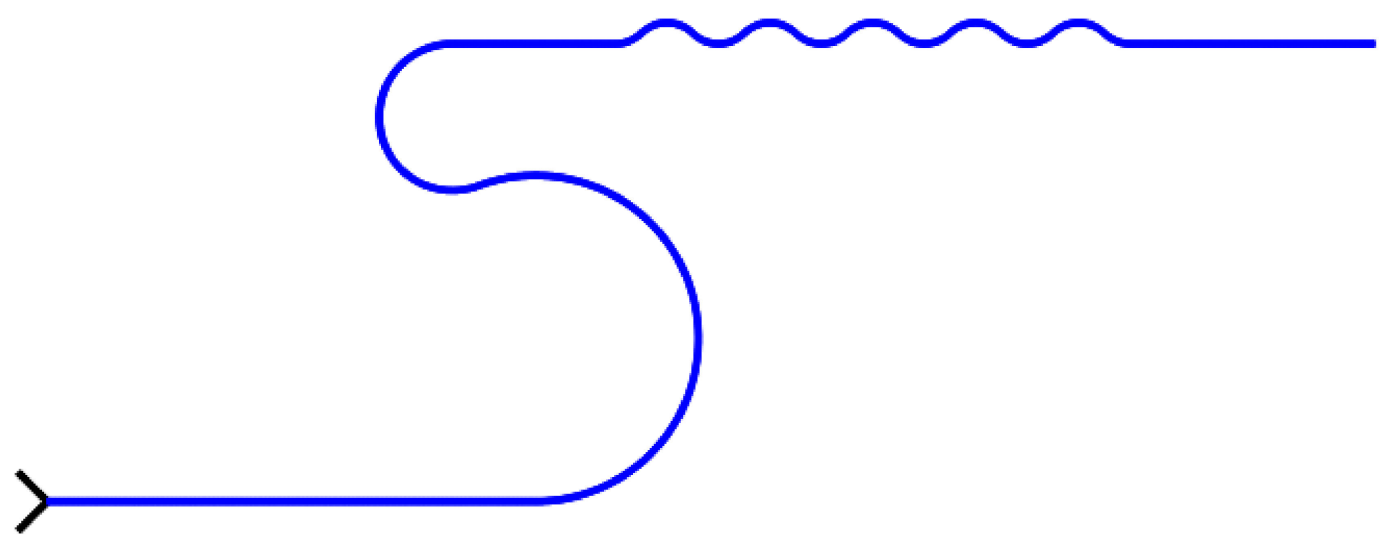

Figure 5. Simulation track configuration.

By introducing the parameters of BS 19 in OptimumLap ${ }^{\circledR}$, the simulated lap time is $19.62 \mathrm{~s}$. If we graph the car speed (Figure 6), longitudinal acceleration (Figure 7), and lateral acceleration (Figure 8), we get the following results:

The last input we need in order to have a complete picture of how the models react is a road profile. Naturally, the best signal used in this situation would be one created based on the scanning of the competition track. However, since the configuration of the competition track is changed every year, the collection of such data would be both time-consuming and expensive. In order to solve this problem, a generic but realistic road profile is generated using the method provided by Agostinacchio and Ciampa [19], based on Fourier series.

Another important advantage of using this method when generating the road profile is the fact that the method proposed by Agostinacchio and Ciampa can generate roads of different roughness levels. Although the quality of the road used in this paper would be considered to be in excellent condition (Class A according to ISO8608), because the competition is held on an FIA certified circuit for Formula 1, this will make the constructed code in this paper more flexible to different cars and road conditions.

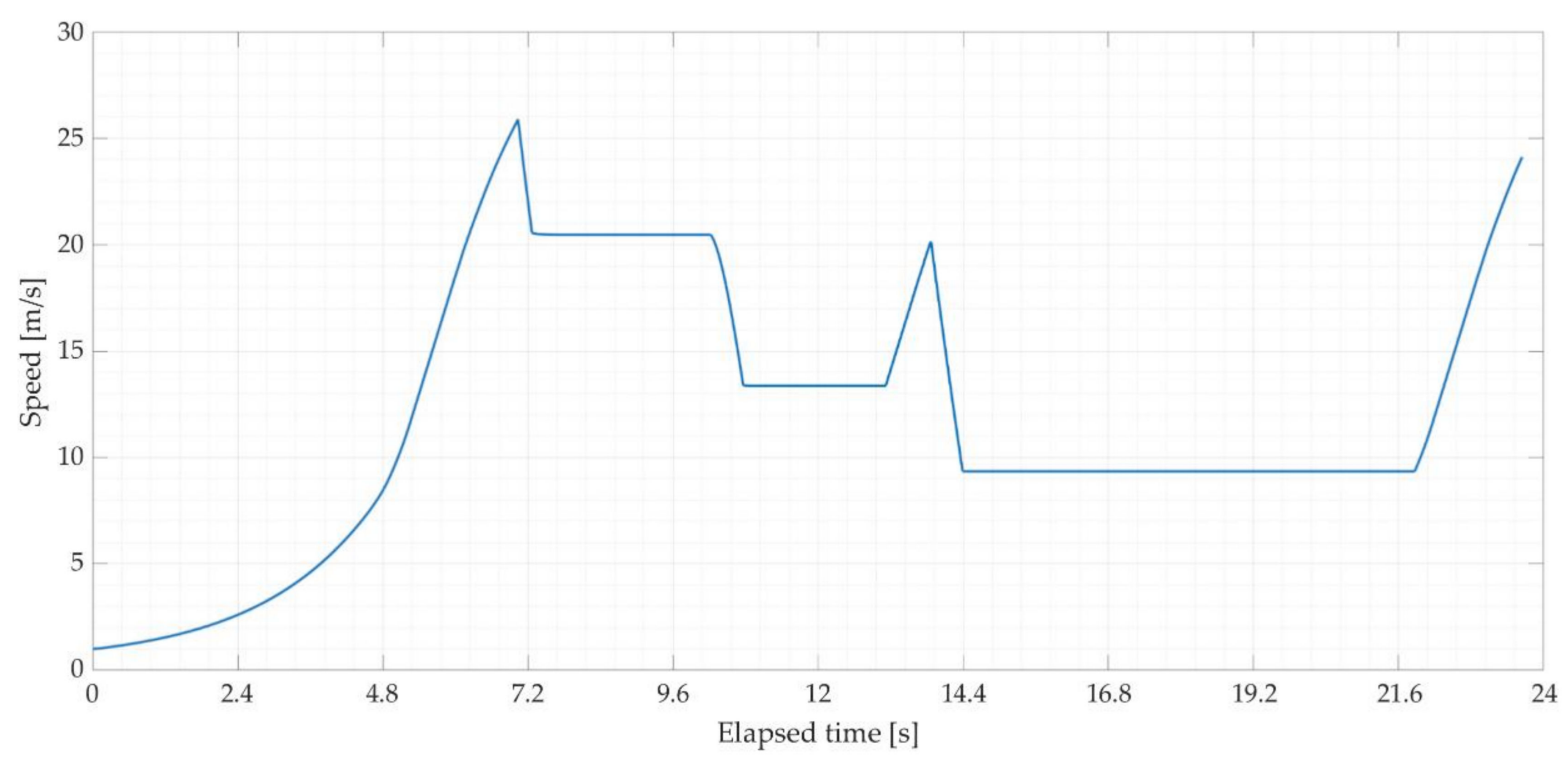

Figure 6. Speed versus lap time. 


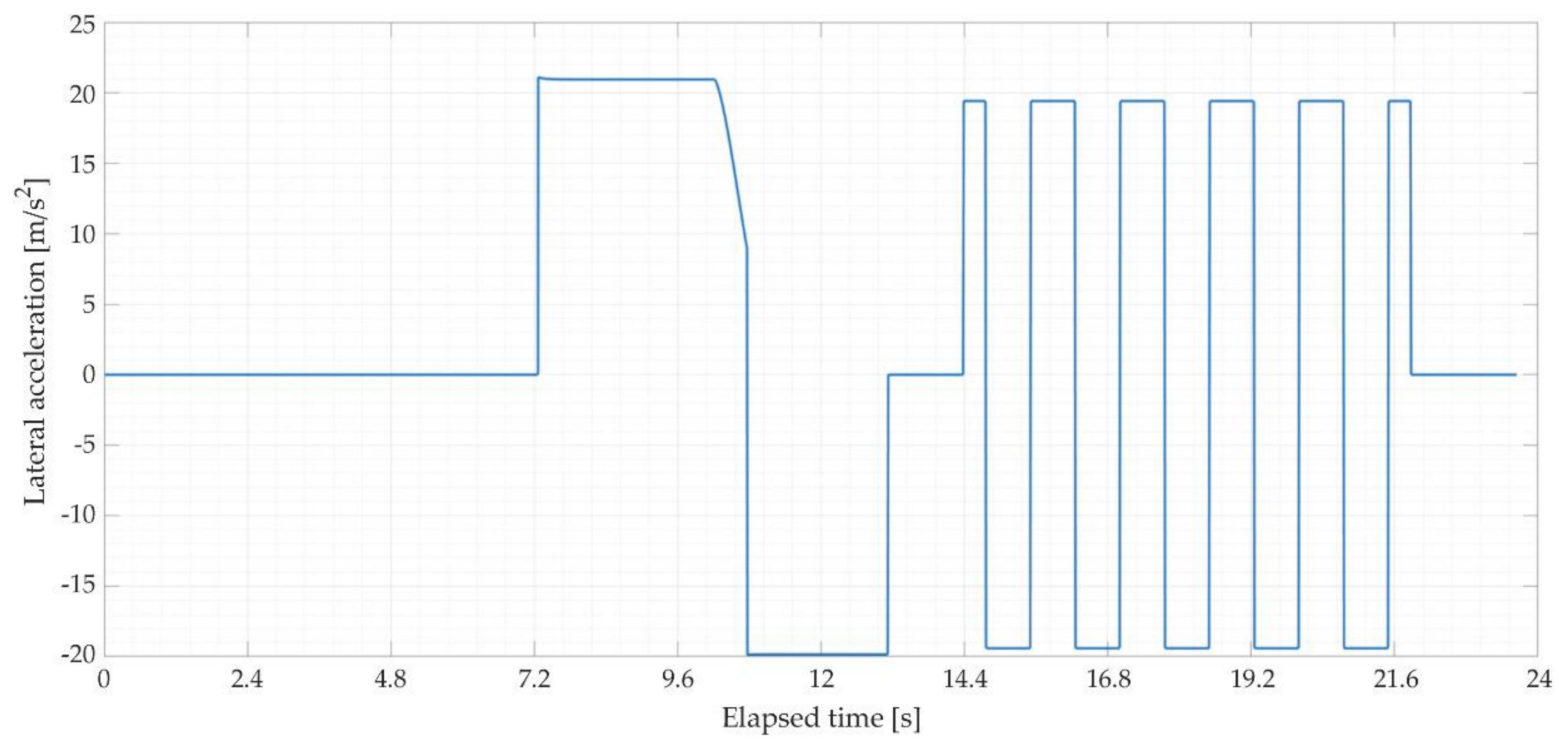

Figure 7. Lateral acceleration versus lap time.

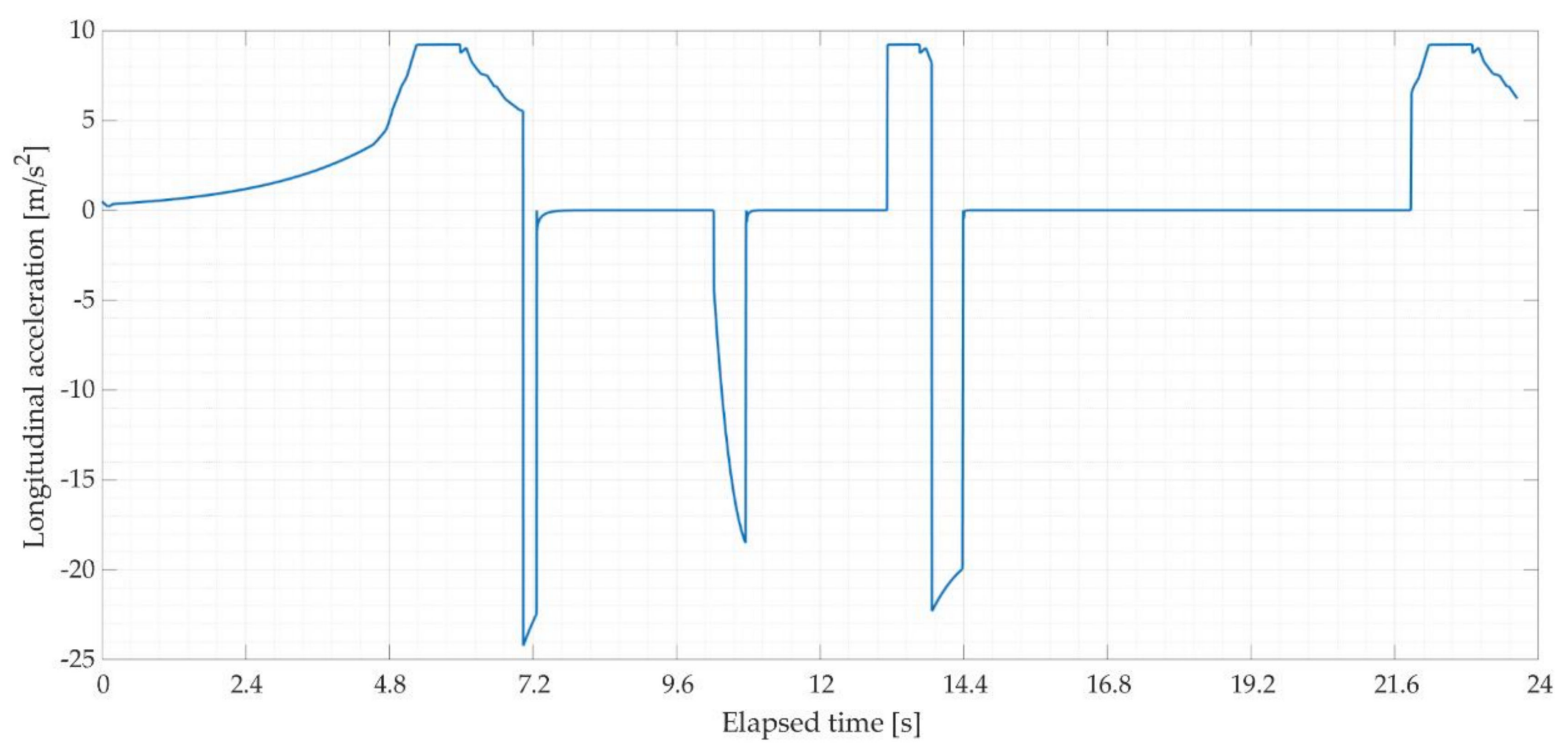

Figure 8. Longitudinal acceleration versus lap time.

Different road profiles specific to a Formula Student track are randomly generated for left and right wheels. These road profiles are calculated with the method proposed by Agostinacchio and Ciampa. Given that the competitions in which team BlueStreamline participates in are usually held on racing tracks, the quality of the paved surface is very good. Therefore, the generated road profiles belong to Class A according to ISO8608.

The equation used to generate the road profile is [19]

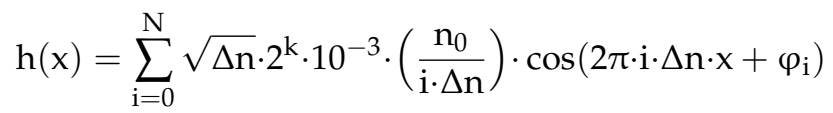

where

$\mathrm{x}$-is the abscissa variable from 0 to $\mathrm{L}$;

$\Delta \mathrm{n}-1 / \mathrm{L}$;

$\mathrm{L}$-length of the road $[\mathrm{m}]$;

$\mathrm{n}_{0}$-Spatial frequency $[1 / \mathrm{m}]$;

$\Phi$-random phase angle following a uniform probabilistic distribution within the $0-2 \pi$ range; 
k-constant value depending from 3-9 depending on the road level ISO classification ranging from $\mathrm{A}$ to $\mathrm{H}$.

The rear wheels of the vehicle follow the same road profile as the front wheels with a delay that is equal to the wheelbase of the vehicle divided by the traveling speed.

Using Equation (32), the following road profile were generated (Figure 9) with the power spectral density shown in Figure 10:

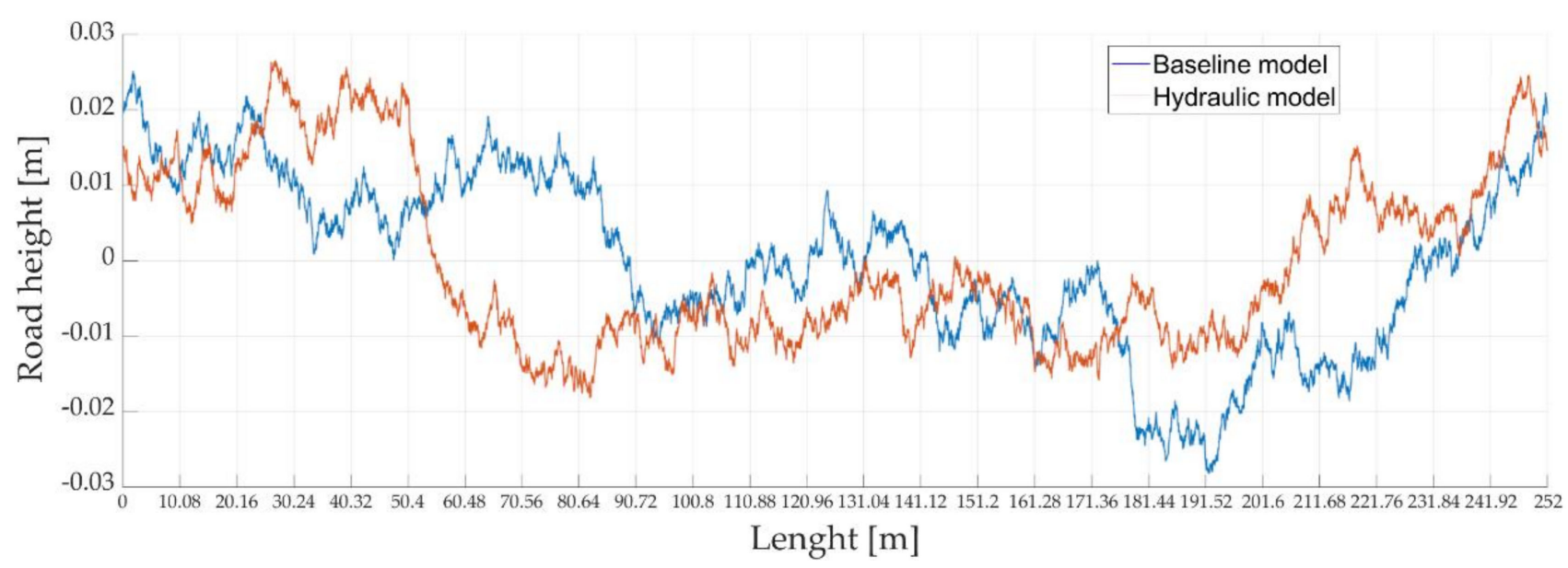

Figure 9. Example of a generated class A road profiles.

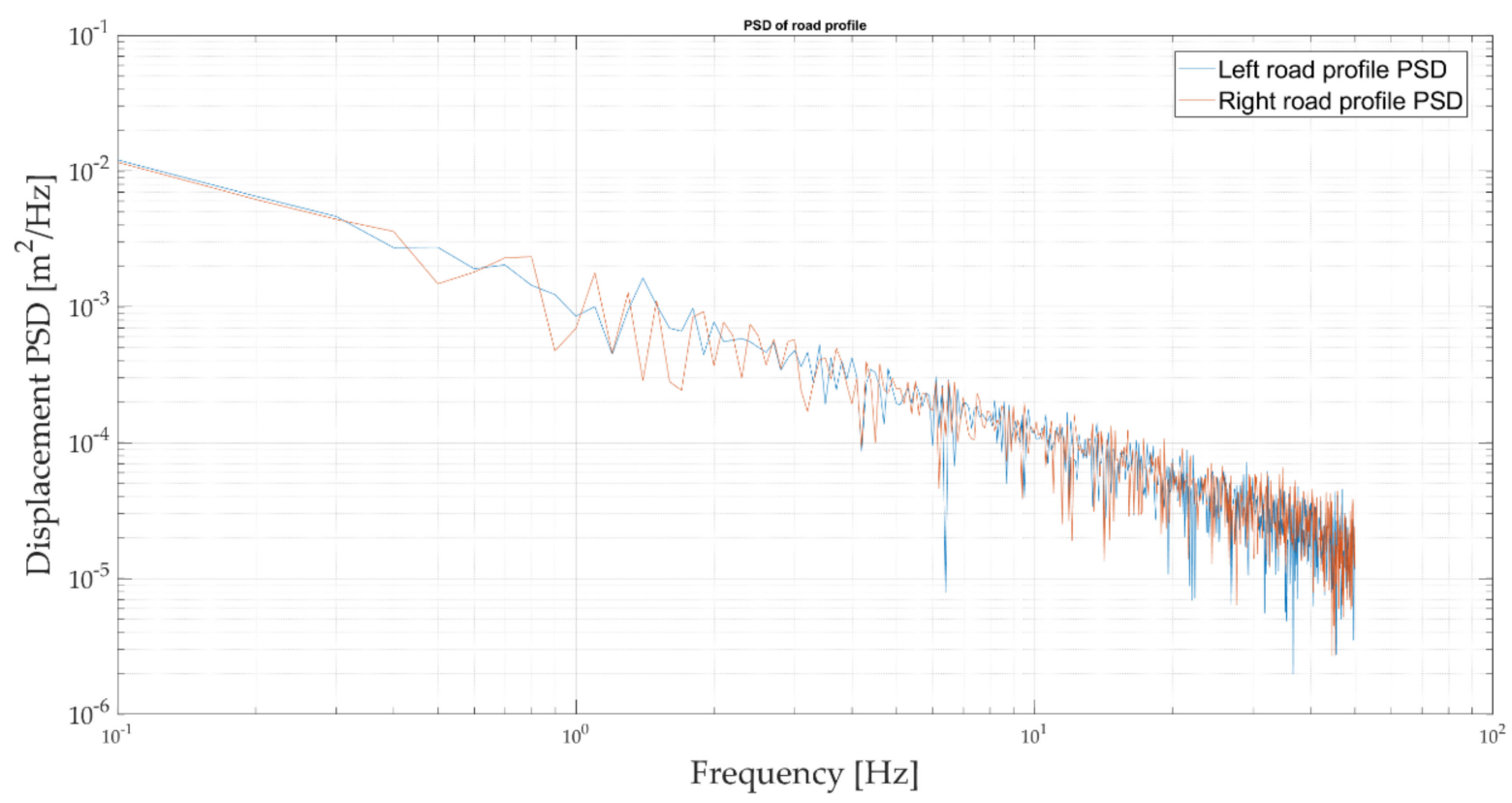

Figure 10. Road profile PSD.

\section{Results}

\subsection{Constant Velocity Simulation}

As stated in the introduction, the first set of simulations will be done when the vehicle travels with a constant velocity. This will be done to study how the vibrating system reacts when the only outside excitation is given by the road profile. As such, the speed of the vehicle will be held constant at $25 \mathrm{~m} / \mathrm{s}$ for a total simulation time of $24 \mathrm{~s}$. Although this situation is not very relevant in a racing situation, it is useful in establishing the baseline behavior of both vehicles. The results are as follows. 
The bounce natural frequencies of the two models were obtained from a reference model with one degree of freedom with a single spring and bounce natural frequency $2 \mathrm{~Hz}$. For the roll mode of vibration, the natural frequencies were calculated with the desired roll gradient of $0.5 \mathrm{deg} / \mathrm{g}$ and the pitch natural frequency with the desired pitch gradient of $0.75 \mathrm{deg} / \mathrm{g}$. The natural frequencies of the models are show in Appendix A.

Looking at the picture from below (Figures 11-15), we can see that the vibrating responses of the bounce and pitch are almost identical in both amplitude and frequency between the two systems. This is expected behavior, because the irregularities of the road level tested are not big enough to produce disturbances of those modes. However, in this simulation, the surprising result is one of the roll responses. Here, the hydraulically interconnected suspension system presents a higher degree of instability when compared with the traditional passive suspension layout.

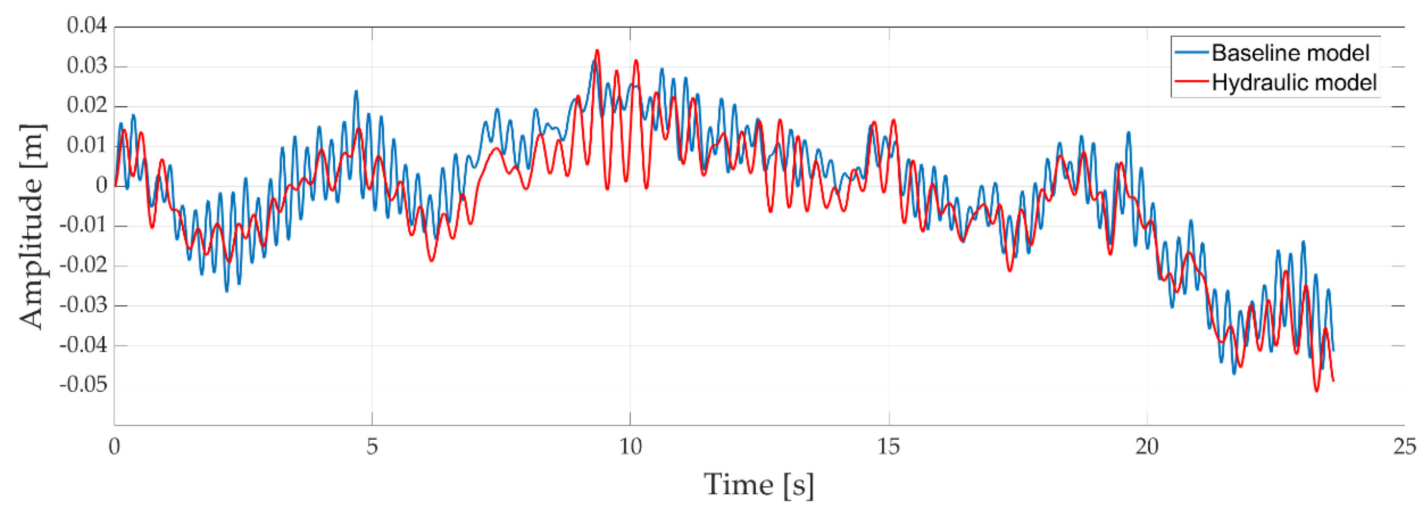

Figure 11. The bounce response to a realistic road profile.

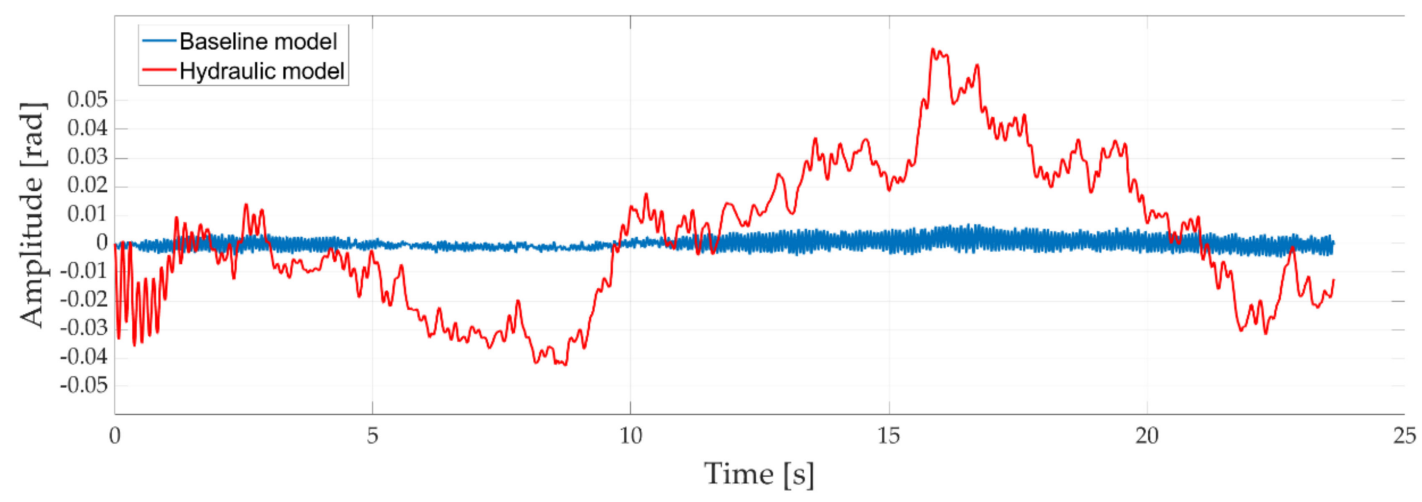

Figure 12. The roll response to a realistic road profile.

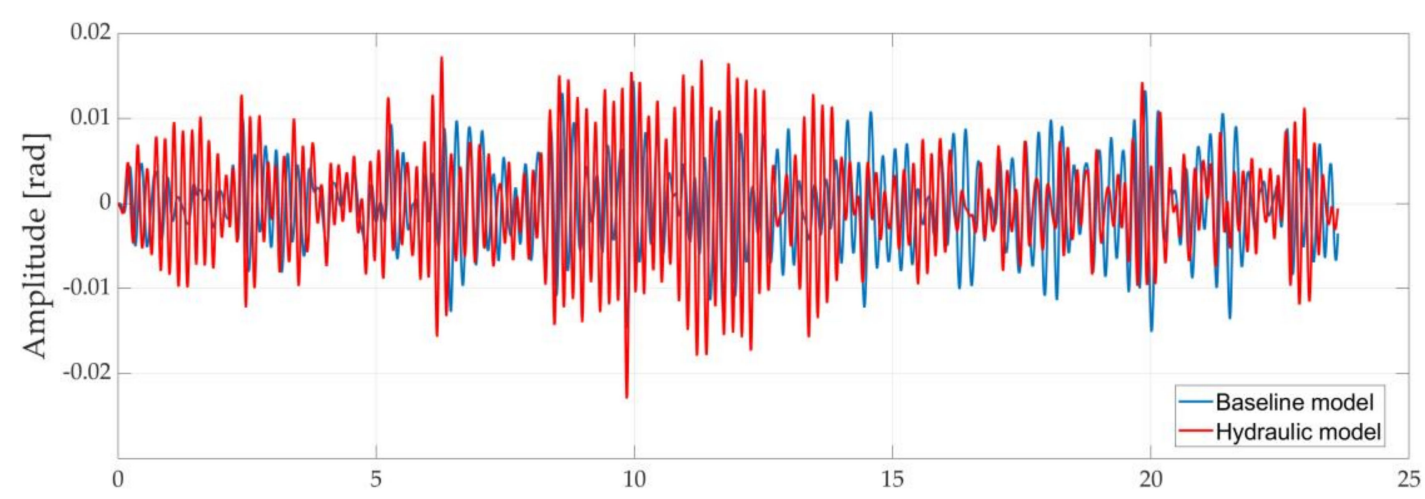

Figure 13. The pitch response to a realistic road profile. 


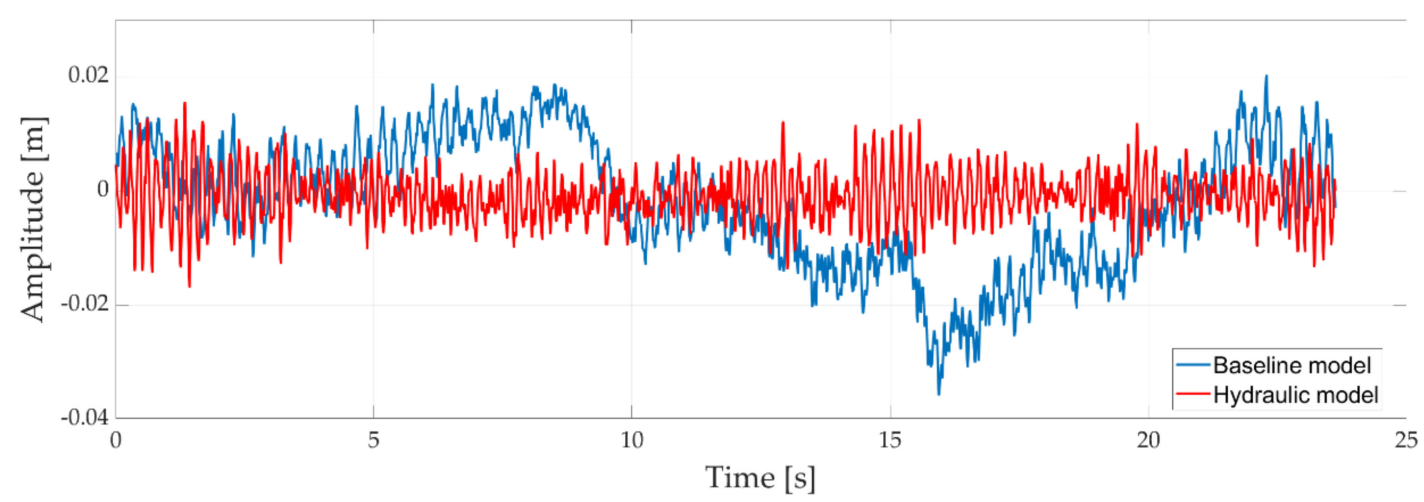

Figure 14. Front left wheel vertical motion relative to the road over a realistic road profile.

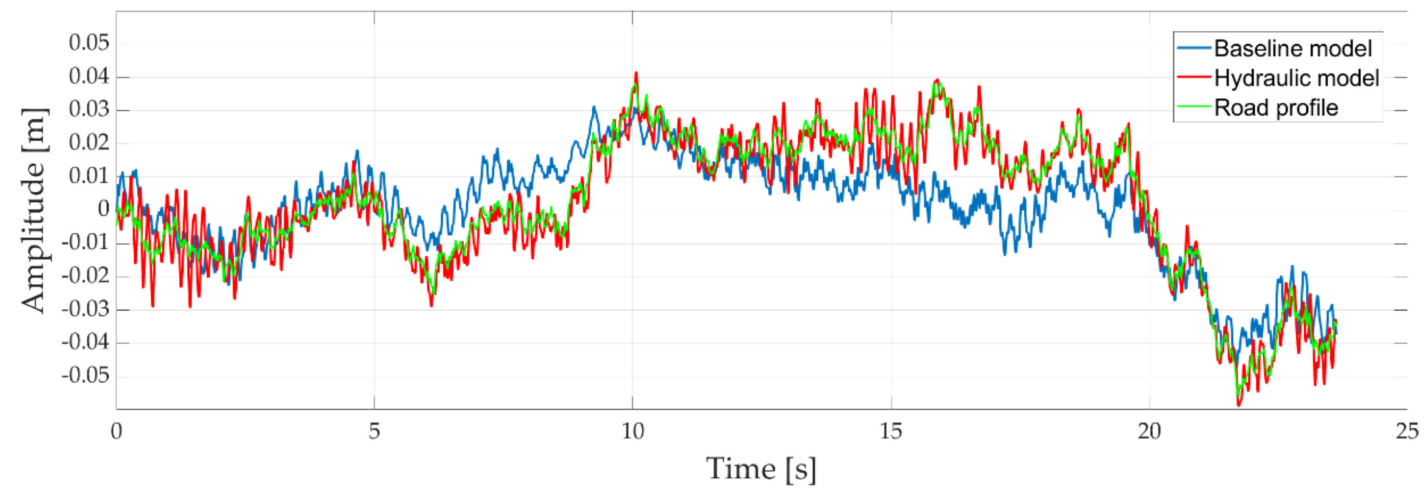

Figure 15. Front left wheel absolute vertical motion over a realistic road profile.

The hydraulic interconnected suspension system, however, has a better performance when it comes to the ability of the wheel to follow the road profile, which, as has been established in the introduction, is vital to the generation of the mechanical grip. This can be clearly seen in Figure 14, where the relative motion of the wheel to the road is smaller than the traditional passive suspension system.

In order to make sure that the result is consistent under the tested circumstances, the simulation is run 20 times with different road profiles from the same roughness class and the results are collected using the root means square of all data points. Using this method, we get the following results.

As expected, the bounce response is almost identical between the 2 models (Figure 16), while the roll response is better for the traditional suspension system (Figure 17). Another expected result is the ability of the wheel to follow the profile of the road (Figure 18) where the hydraulic interconnected suspension system allows the wheel to follow the road profile more closely. However, the surprising conclusion we can draw from this simulation is the fact that the traditional passive suspension system, besides having poorer relative results, also has a much more inconsistent response for different road profiles that are in the same ISO roughness class. Another surprising conclusion is the pitch response of the hydraulically interconnected suspension system (Figure 19), which has a higher degree of pitch instability likely due to the higher frequency of the response. 


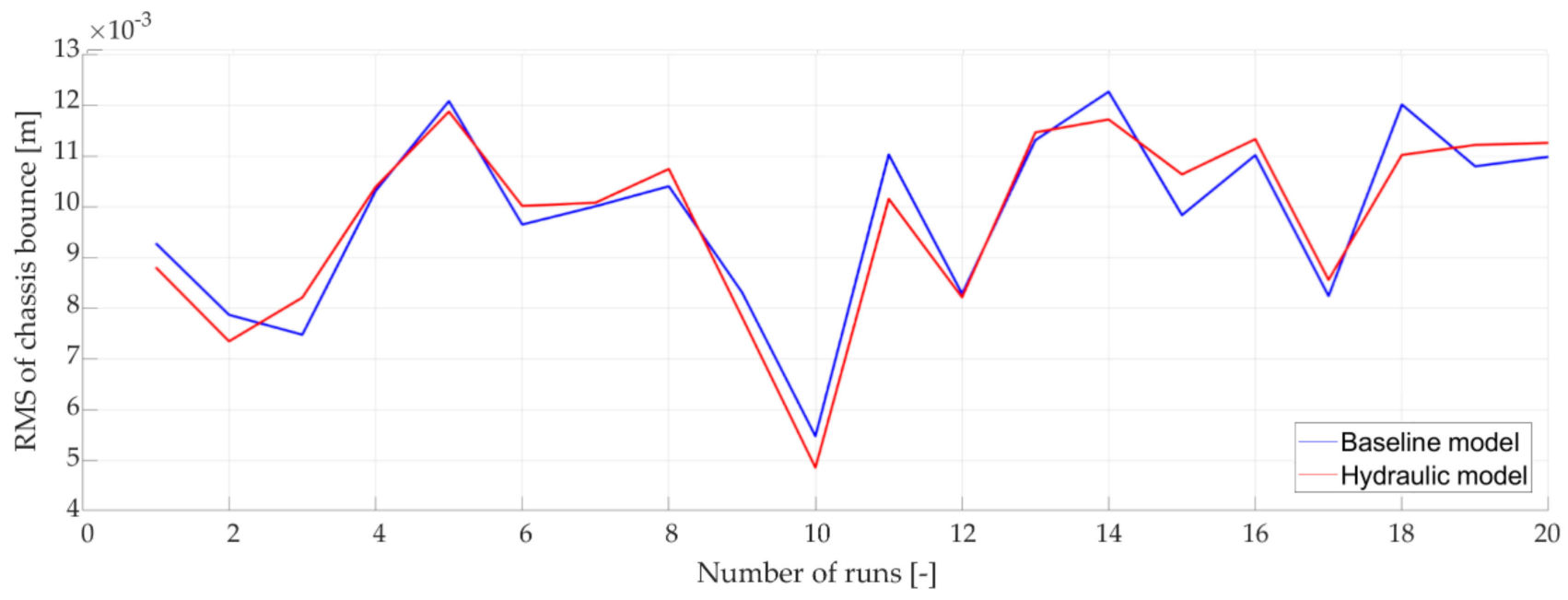

Figure 16. Chassis bounce root mean square for a realistic road profile.

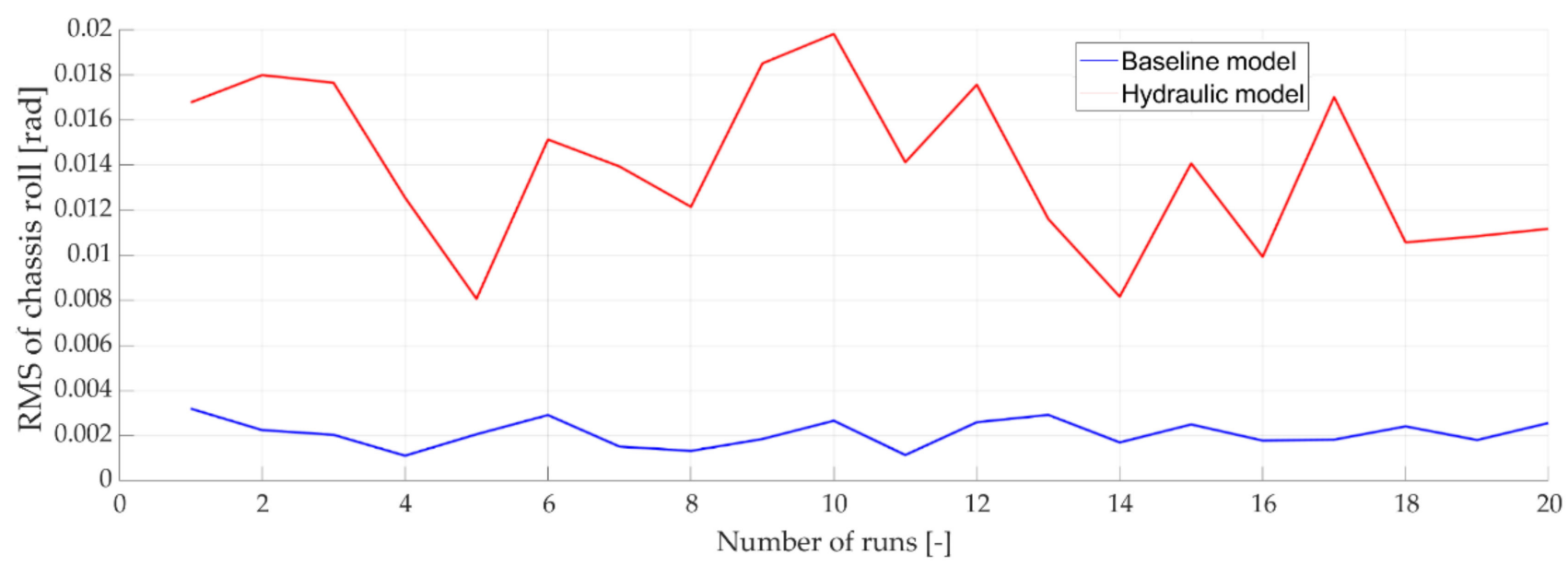

Figure 17. Chassis roll root means square for a realistic road profile.

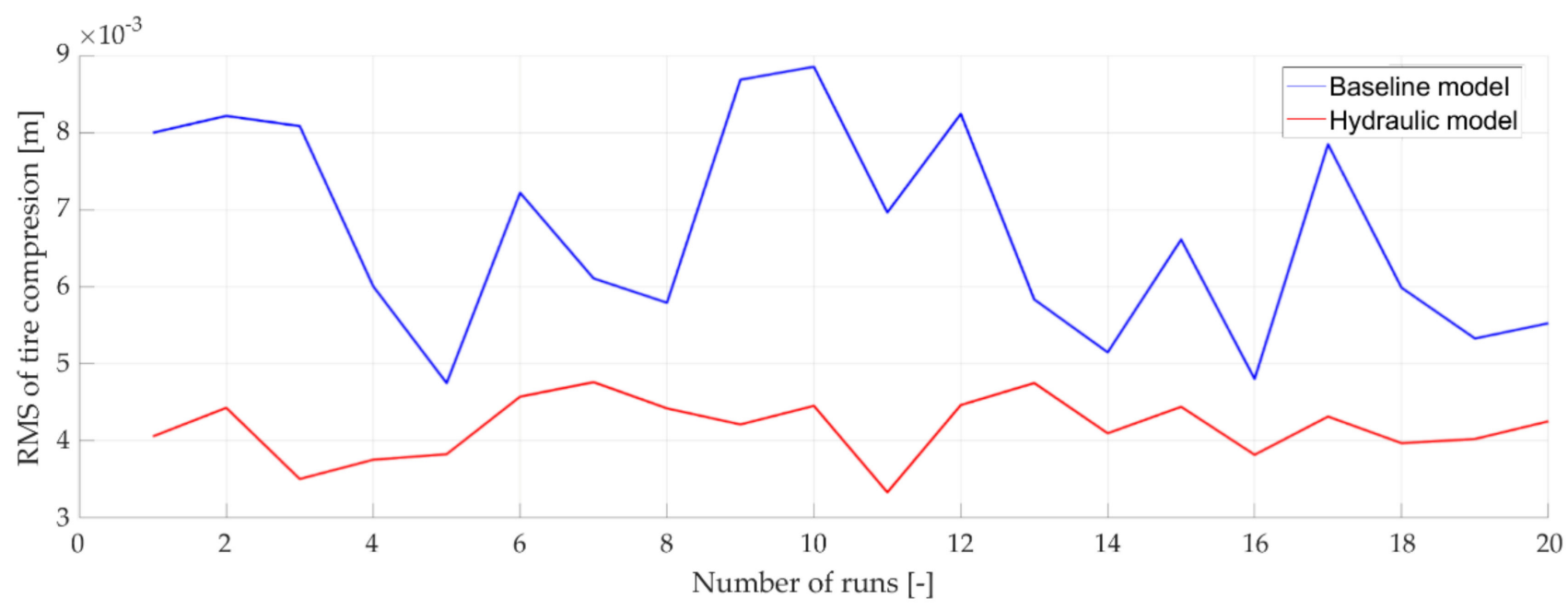

Figure 18. The root means square of the front left wheel vertical motion relative to the road. 


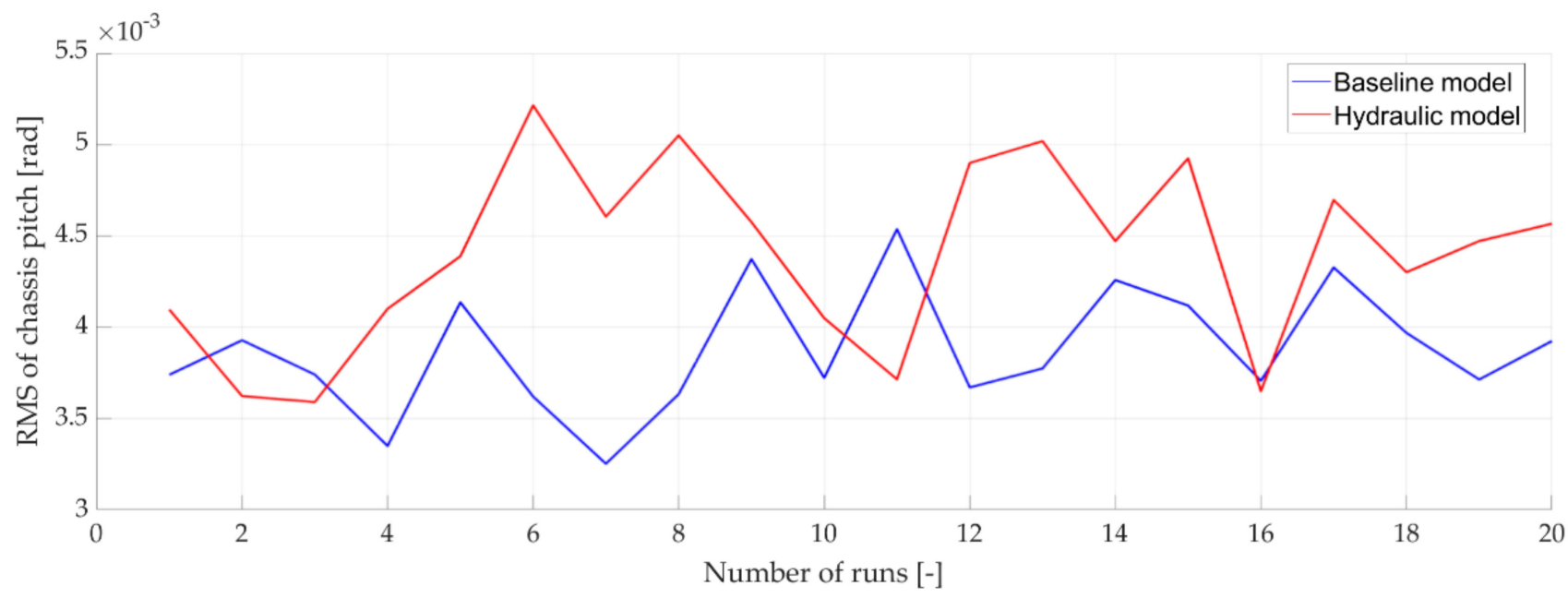

Figure 19. Chassis pitch root mean square for a realistic road profile.

\subsection{Dynamic Simulation}

The dynamic simulation is done by introducing traveling velocities (Figure 6), the lateral accelerations (Figure 7), and longitudinal accelerations (Figure 8) in the EOM from Sections 2.1.1 and 2.1.2. Since the velocities are not constant, as opposed to the first set of simulations, the delay with which the rear wheel follows the front wheel will vary depending on the traveling velocity of the car. Therefore, the road profile for the front and rear wheels will take the following form (Figure 20).

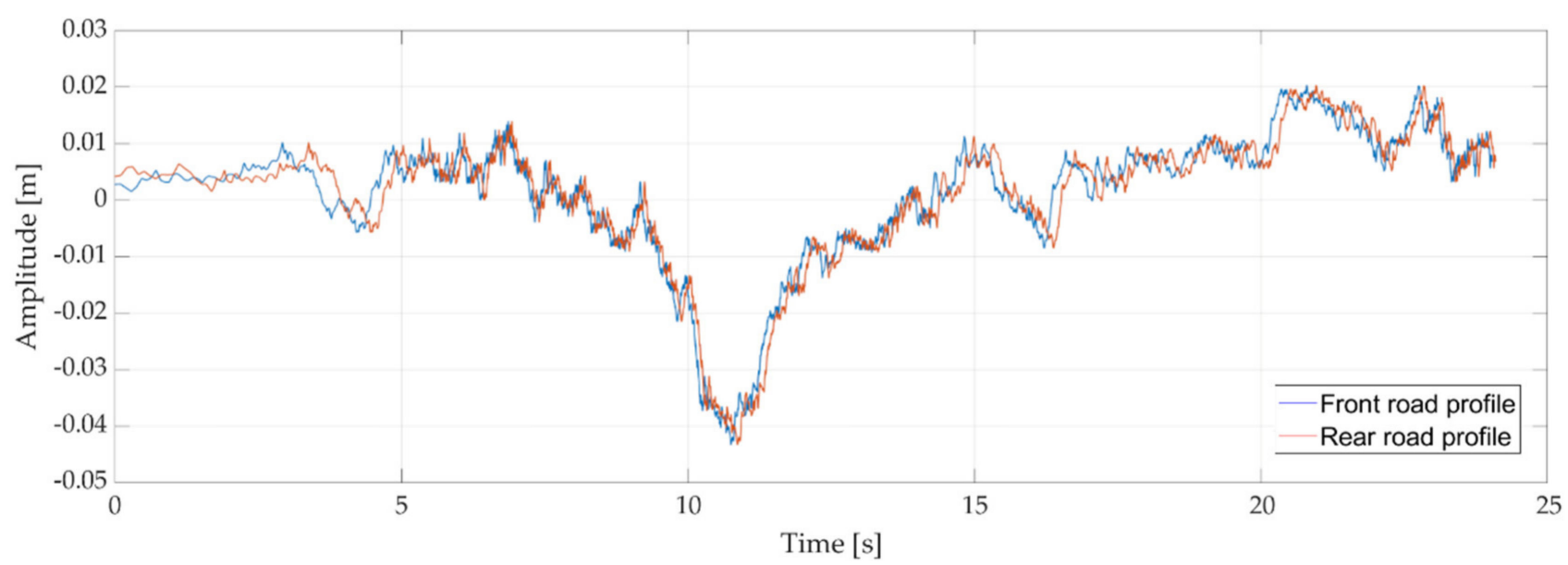

Figure 20. Example of the delay between the front and rear wheels of the vehicle.

The results of the simulation with a realistic road profile on a simulated track are as follows.

In this simulation case, we can again see that the roll response of the hydraulically interconnected suspension system has a much higher amplitude of the vibrating response when compared to the traditional passive suspension system (Figure 21). The bounce response of both systems (Figure 22) is again almost identical in amplitude, although the frequency of the response is higher for the traditional suspension system. When it comes to the mechanical grip performance, the hydraulically interconnected suspension system presents a much smaller relative motion to the road (Figures 23 and 24) and therefore superior mechanical grip. Another advantage of the proposed suspension system in this simulation case is the better pitch response (Figure 25), which correlates with better aerodynamic performances. 


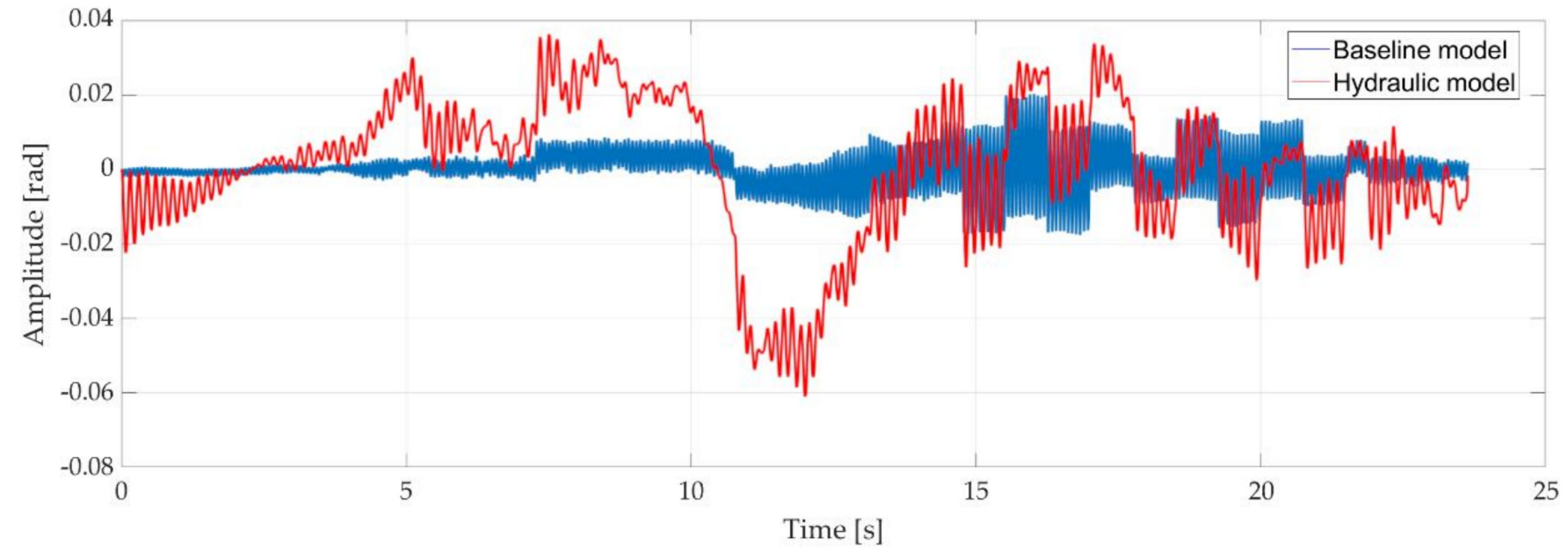

Figure 21. The roll response to a realistic road profile and external accelerations.

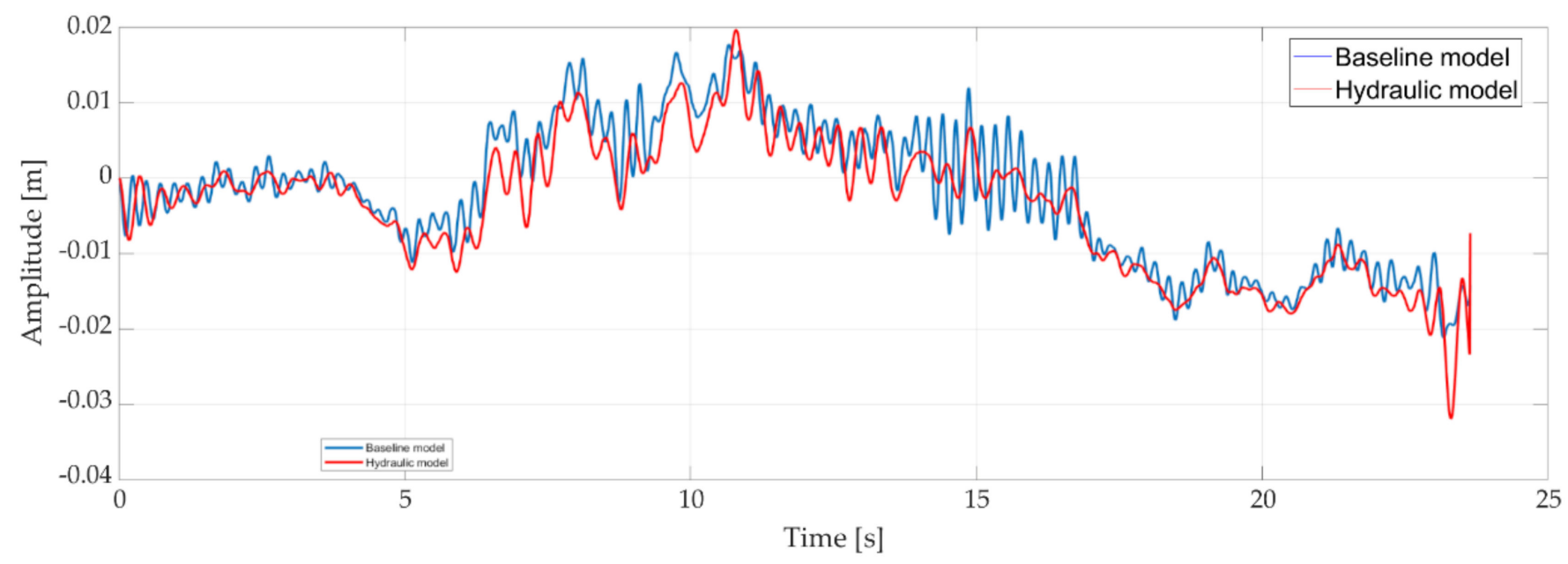

Figure 22. The bounce response to a realistic road profile and external accelerations.

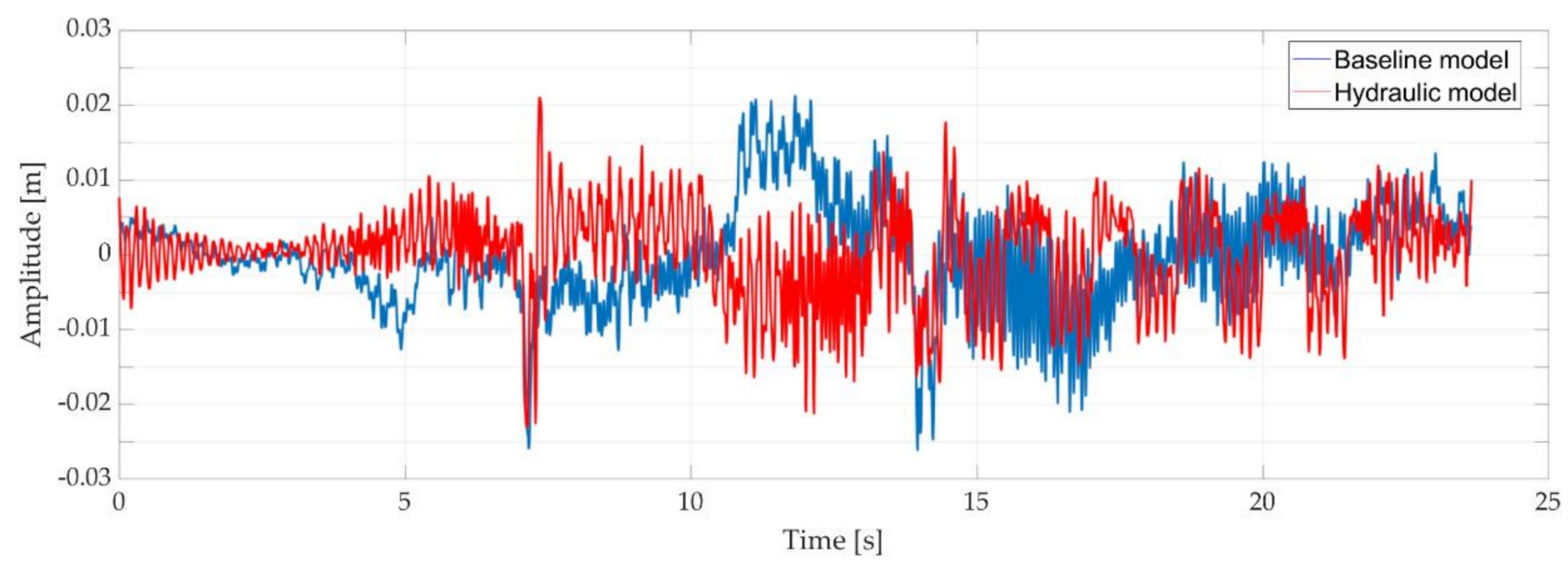

Figure 23. Front left wheel vertical motion relative to a road with a realistic profile and external accelerations. 


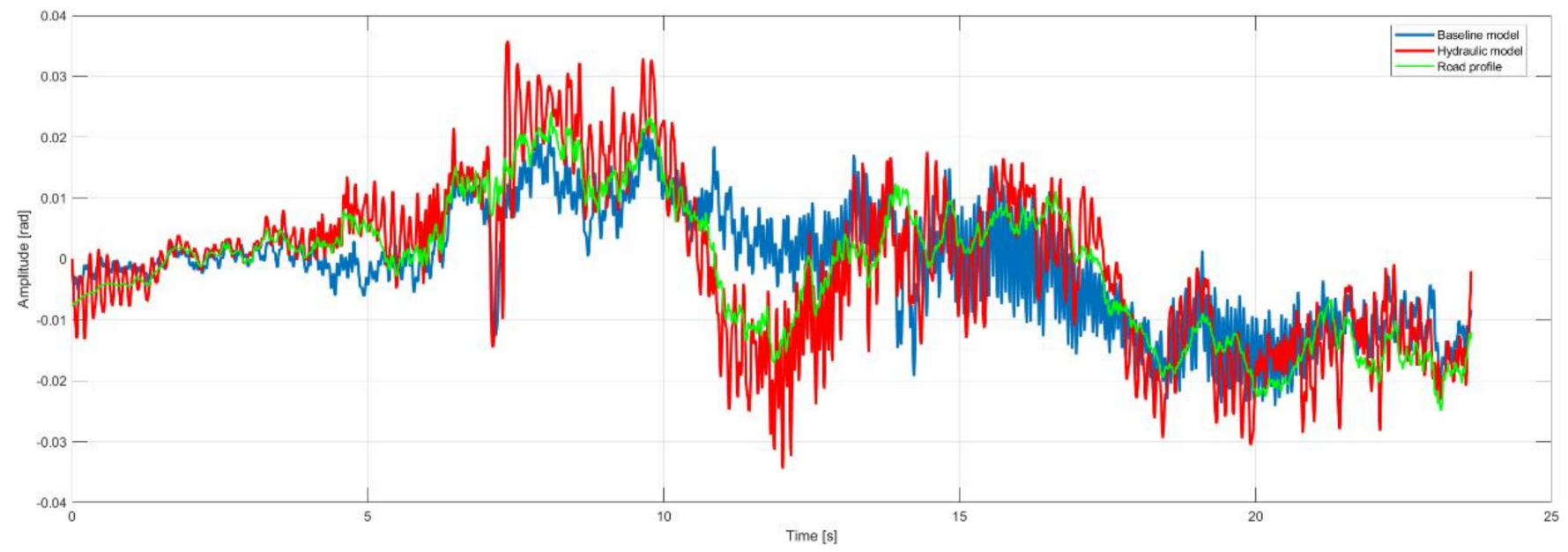

Figure 24. Front left wheel absolute vertical motion over a realistic road profile and external accelerations.

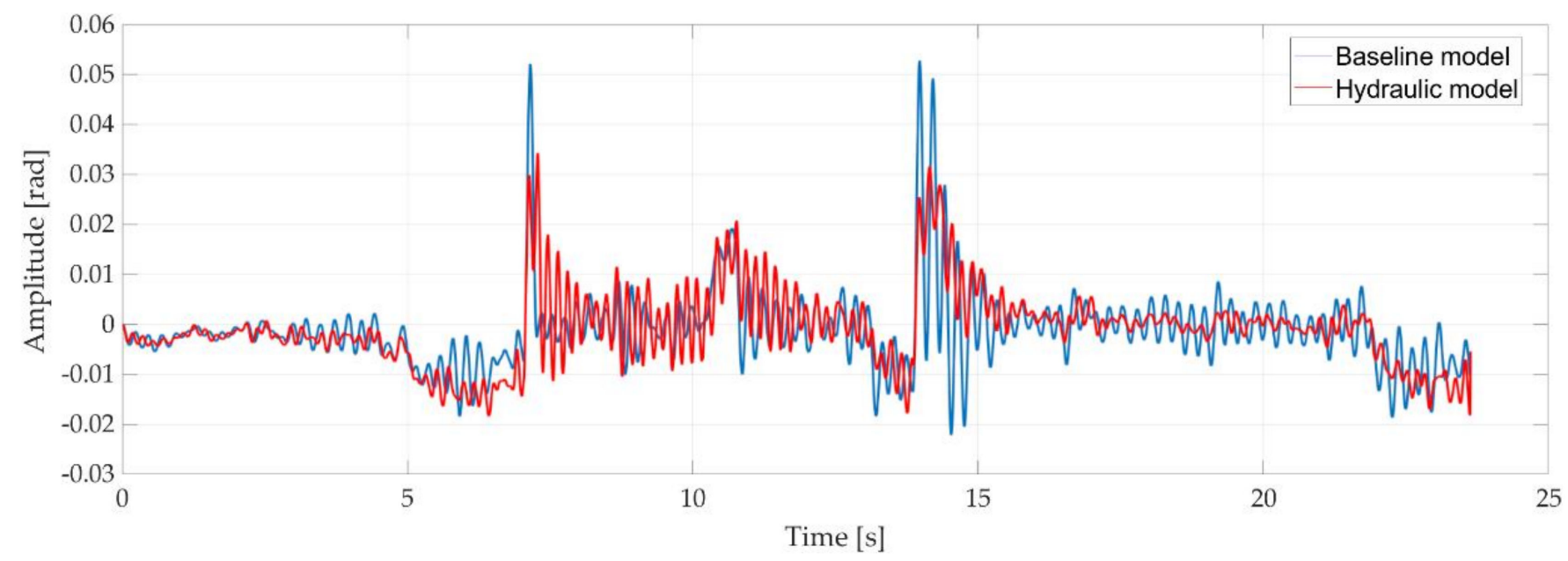

Figure 25. The pitch response to a realistic road profile and external accelerations.

As in the previous case, each simulation is run 20 times and the root mean square is registered to ensure that the displayed results are not statistical anomalies.

As was the case in the simulation run with a constant velocity, we can see that the hydraulically interconnected suspension system offers a better mechanical grip (Figure 26) due to the much lower relative motion of the wheel to the road. Additionally, it also offers a more consistent response for different road profiles in the same ISO class. The bounce responses of the two models are the same (Figure 27) and the roll response of the hydraulically interconnected suspension system has higher amplitude (Figure 28).

One difference from the previous simulation is the pitch response (Figure 29). When the external accelerations of the vehicle generated during acceleration/braking and cornering are taken into account, the hydraulic interconnected suspension system offers a more stable vibrating response with obvious advantages for the aerodynamic performance of the car. 


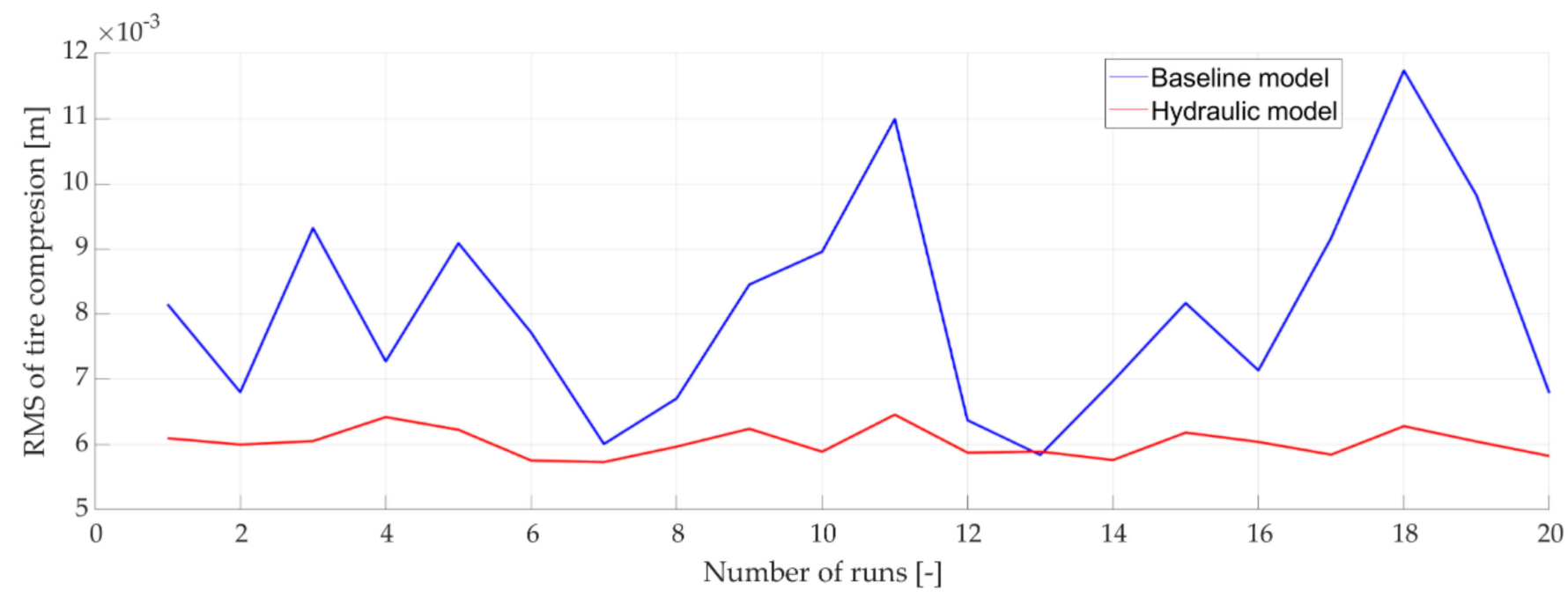

Figure 26. The root means square of the front left wheel vertical motion relative to the road.

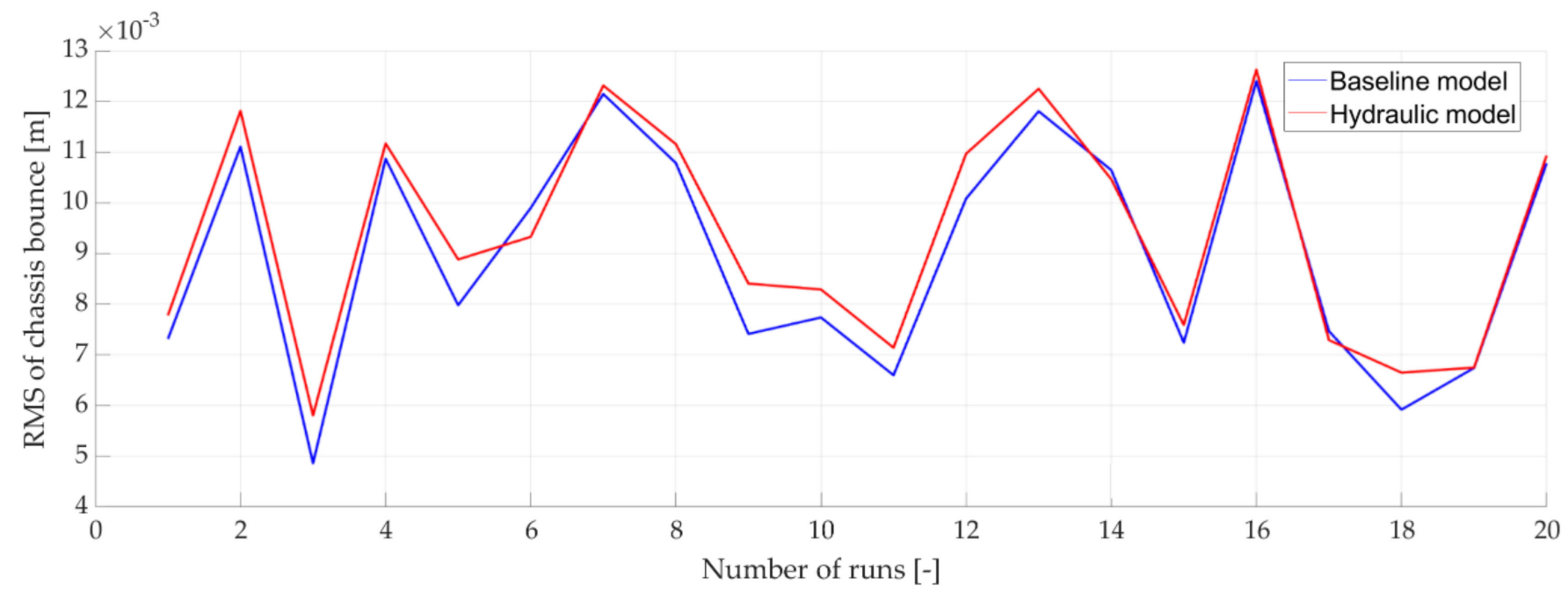

Figure 27. Chassis bounce root mean square for a realistic road profile and external accelerations.

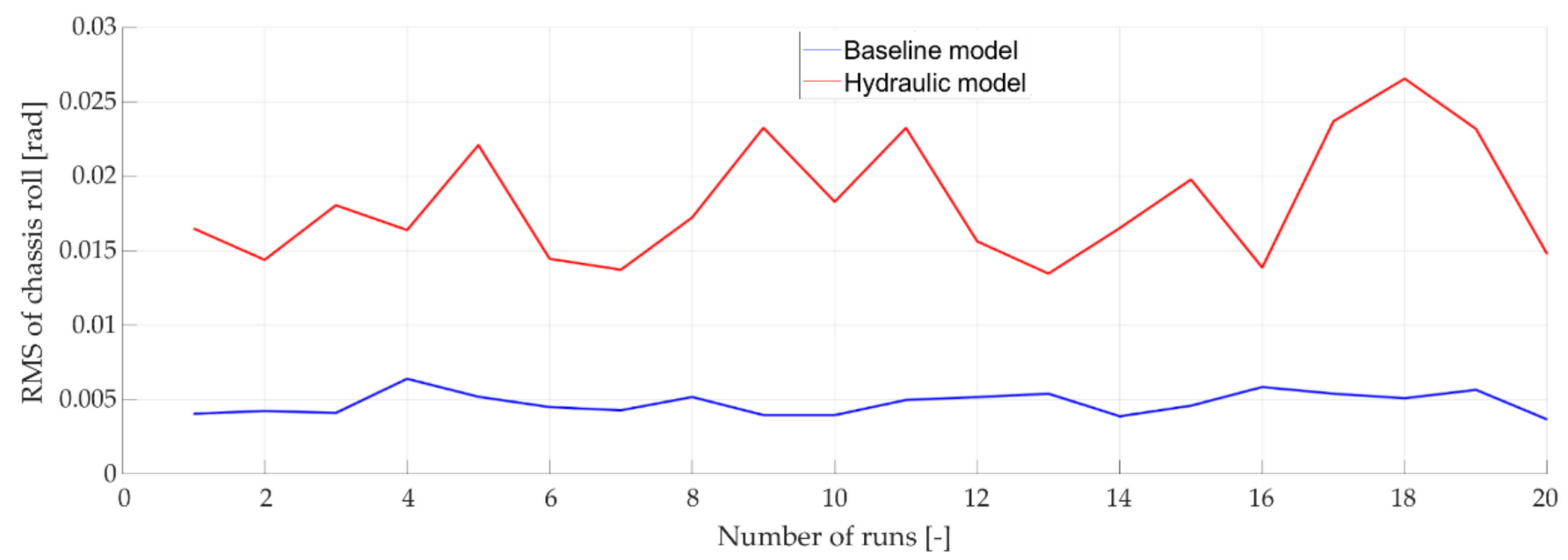

Figure 28. Chassis roll root means square for a realistic road profile and external accelerations. 


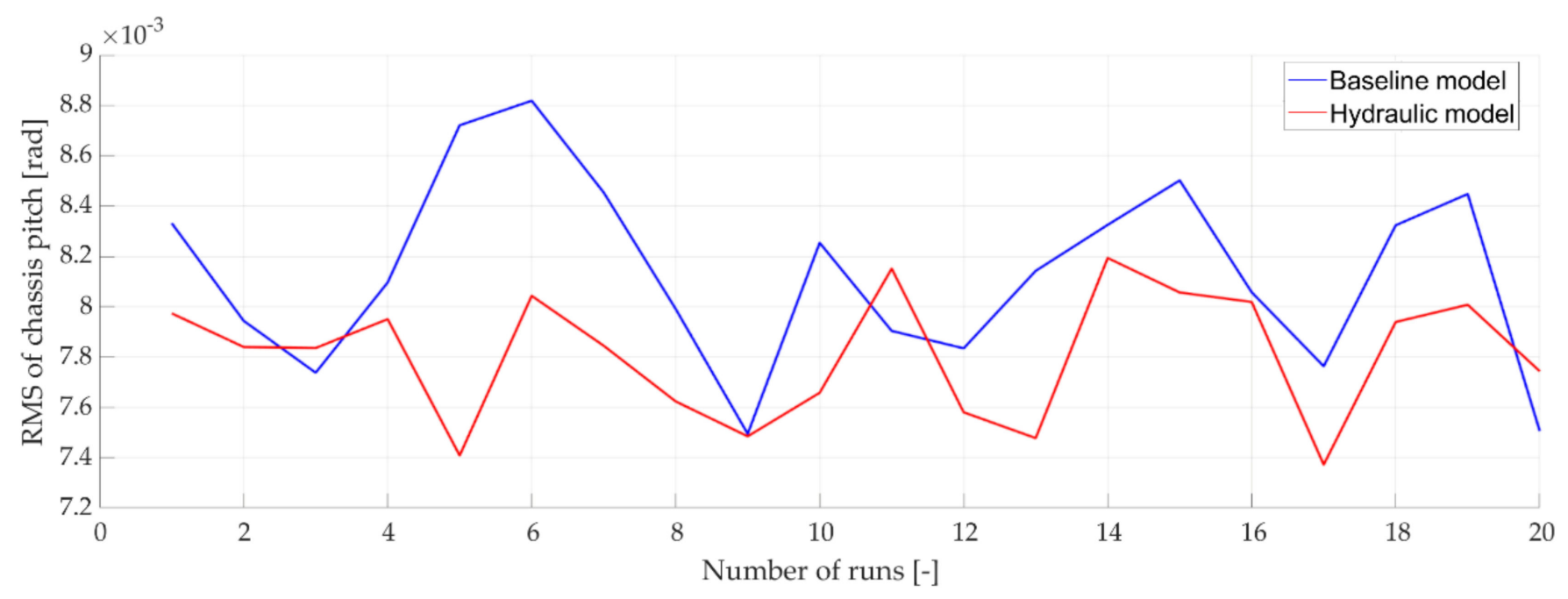

Figure 29. Chassis pitch root mean square for a realistic road profile and external accelerations.

\section{Discussion}

The purpose of this paper was to test the theoretical performances of the hydraulic interconnected suspension system by comparing the simulated results against the ones obtained from a traditional passive suspension system with front and rear ARBs. Two performance parameters were chosen as essential for increasing the dynamic performance of the car based on the study of the performance envelope: the ability of the wheel to follow the road profile (which can be correlated with mechanical grip) and pitch stability (which is beneficial to downforce generation). However, giving the fact that the chosen vehicle for the simulation runs only in Formulas Student competitions, the mechanical grip improvement is more valuable.

The primary advantage of the system proposed by Smith and Walker for the hydraulically interconnected suspension system is the increase of mechanical grip as a result of the fact that the stiffness of the wrap mode can be eliminated [2]. Judging by the results in this paper, this hypothesis seems to be correct: in both the steady state and dynamic simulations, the wheels of the interconnected suspension systems have much lower relative displacements relative to the road. Another advantage of the proposed system is the ability to choose the pitch stiffness of the vehicle independently of all the other elastic elements of the suspension system. Due to this advantage, the pitch stability of the car was improved, when compared with the traditional passive suspension, with beneficial effects on downforce generation.

Judging the two systems described in this paper by only these two performance factors, it is clear that the hydraulically interconnected suspension system is the superior choice when compared with the traditional passive suspension system. However, it is important to note that certain simplifications were done to decrease the computational time necessary to solve the EOMs of both models. The most notable simplification made was using ideal conduits and fittings. Giving this simplification, the pressure loss that is present in any hydraulic systems due to diameters and lengths, the shape and construction of the fittings, and their overall effects of the type of flow of the hydraulic fluid is not considered in this model. As a result, the performances of a real-life hydraulically interconnected suspension can present some differences from the presented mathematical model due to the architecture of the hydraulic system itself.

Another important simplification made to the system is the idealization of the hydraulic fluid. In the current model, the hydraulic fluid was considered incompressible and therefore acted as an ideal lever. However, any material is compressible to some degree [20]. This property of the hydraulic fluid can create some problems since in a double-acting cylinder, like the ones used for the construction of a hydraulically interconnected suspension system, the compressibility of the fluid can act as two springs, acting in parallel, pushing 
against the piston [20]. This means that for simulations done at higher frequencies, the resonance of the hydraulic fluid itself can affect the simulation results. This problem is further compounded by the fact that if the air is dissolved in the hydraulic fluid or water contamination occurs, the bulk modulus of the fluid will decrease therefore decreasing the resonance frequency of the fluid.

These problems, along with various environmental factors that might affect the flow of the hydraulic fluid (such as temperature), can be considered logically as the next necessary step in simulating and constructing such a system for either racing or industrial or general transport purposes.

Author Contributions: Conceptualization, all authors; methodology, A.-C.P.; software, all authors; validation, C.A.; writing — original draft preparation, A.-C.P.; writing—review and editing all authors; supervision, C.A. Both authors have read and agreed to the published version of the manuscript.

Funding: This work was supported by a grant of the Romanian Ministry of Research, Innovation and Digitization, CNCS/CCCDI-UEFISCDI, project number PN-III-P2-2.1-PED-2019-4366 (431PED), within PNCDI III.

Institutional Review Board Statement: Not applicable.

Informed Consent Statement: Not applicable.

Data Availability Statement: Not applicable.

Conflicts of Interest: The authors declare no conflict of interest.

Appendix A.

Table A1. Vehicle Parameters.

\begin{tabular}{ccc}
\hline Parameters & Value & Meaning \\
\hline $\mathrm{m}$ & $228[\mathrm{~kg}]$ & Sprung mass \\
$\mathrm{m}_{\mathrm{f}}$ & $10[\mathrm{~kg}]$ & Front unsprung mass \\
$\mathrm{m}_{\mathrm{r}}$ & $11[\mathrm{~kg}]$ & Rear unsprung mass \\
$\mathrm{I}_{\mathrm{xx}}$ & $28.4\left[\mathrm{~kg} / \mathrm{m}^{2}\right]$ & Roll moment of inertia \\
$\mathrm{I}_{\mathrm{yy}}$ & $103.2\left[\mathrm{~kg} / \mathrm{m}^{2}\right]$ & Pitch moment of inertia \\
$\mathrm{F}_{\mathrm{NSM}} \mathrm{NGh}$ & $235[\mathrm{~mm}]$ & Front non-suspended mass CG height \\
$\mathrm{R}_{\mathrm{NSM}} \mathrm{NGGh}_{\mathrm{C}}$ & $235[\mathrm{~mm}]$ & Rear non-suspended mass CG height \\
$\mathrm{CG}_{\mathrm{h}}$ & $350[\mathrm{~mm}]$ & CG height \\
$\mathrm{SMCG}_{\mathrm{h}}$ & $360[\mathrm{~mm}]$ & Suspended mass CG height \\
$\mathrm{a}_{1}$ & $0.793[\mathrm{~m}]$ & Distance from front wheel to CG \\
$\mathrm{a}_{2}$ & $0.732[\mathrm{~m}]$ & Distance from rear wheel to CG \\
$\mathrm{b}_{1}$ & $0.575[\mathrm{~m}]$ & Front half track \\
$\mathrm{b}_{2}$ & $0.550[\mathrm{~m}]$ & Rear half track \\
$\Delta_{\mathrm{zr}}$ & $0.295[\mathrm{~m}]$ & Distance from CG to roll axis \\
$\Delta_{\mathrm{zp}}$ & $0.397[\mathrm{~m}]$ & Distance from CG to PC \\
$\mathrm{F}_{\mathrm{RCh}}$ & $0.05[\mathrm{~m}]$ & Front roll center height \\
$\mathrm{R}_{\mathrm{RCh}}$ & $0.08[\mathrm{~m}]$ & Rear Roll center height \\
$\mathrm{k}_{\mathrm{tf}}$ & $85,000[\mathrm{~N} / \mathrm{mm}]$ & Front tire stiffness \\
$\mathrm{k}_{\mathrm{tr}}$ & $88,000[\mathrm{~N} / \mathrm{mm}]$ & Rear tire stiffness \\
$\rho$ & $1230\left[\mathrm{~kg} / \mathrm{m}^{2}\right]$ & Air density \\
$\mathrm{A}_{\mathrm{f}}$ & $2[\mathrm{~m}]$ & Frontal area of the car \\
$\mathrm{C}$ & $1.3[-]$ & Downforce coefficient \\
\hline
\end{tabular}


Table A2. Passive Suspension Parameters.

\begin{tabular}{|c|c|c|}
\hline Parameters & Value & Meaning \\
\hline $\mathrm{MR}_{\mathrm{f}}$ & $2[-]$ & Front motion ration \\
\hline $\mathrm{MR}_{\mathrm{r}}$ & $1.53[-]$ & Rear motion ration \\
\hline $\mathrm{k}_{\mathrm{f}}$ & $7138[\mathrm{~N} / \mathrm{mm}]$ & Front spring stiffness \\
\hline $\mathrm{k}_{\mathrm{r}}$ & $9172[\mathrm{~N} / \mathrm{mm}]$ & Rear spring stiffness \\
\hline $\mathrm{ARB}_{\mathrm{f}}$ & $3407[\mathrm{Nm} / \mathrm{deg}]$ & Front ARB stiffness \\
\hline $\mathrm{ARB}_{\mathrm{r}}$ & $1965[\mathrm{Nm} / \mathrm{deg}]$ & Rear ARB stiffness \\
\hline $\mathrm{v}_{\mathrm{kf}}$ & $0.2[\mathrm{~m} / \mathrm{s}]$ & Front knee velocity \\
\hline $\mathrm{v}_{\mathrm{kr}}$ & $0.2[\mathrm{~m} / \mathrm{s}]$ & Rear knee velocity \\
\hline$c_{f}$ & $794[\mathrm{Ns} / \mathrm{m}]$ & Front damping rate \\
\hline \multirow[t]{5}{*}{$c_{r}$} & $1022[\mathrm{Ns} / \mathrm{m}]$ & Rear damping rate \\
\hline & $1.76[\mathrm{~Hz}]$ & Bounce natural frequency \\
\hline & $1.9[\mathrm{~Hz}]$ & Roll natural frequency \\
\hline & $5.9[\mathrm{~Hz}]$ & Pitch natural frequency \\
\hline & $1.9[\mathrm{~Hz}]$ & Wrap natural frequency \\
\hline
\end{tabular}

Table A3. Hydraulically Interconnected Suspension Parameters.

\begin{tabular}{ccc}
\hline Parameters & Value & Meaning \\
\hline $\mathrm{MR}_{\mathrm{f}}$ & $2[-]$ & Front motion ration \\
$\mathrm{MR}_{\mathrm{r}}$ & $2[-]$ & Rear motion ration \\
$\mathrm{k}_{\mathrm{b}}$ & $324,000[\mathrm{~N} / \mathrm{mm}]$ & Bounce spring stiffness \\
$\mathrm{k}_{\mathrm{r}}$ & $587,510[\mathrm{~N} / \mathrm{mm}]$ & Roll spring stiffness \\
$\mathrm{k}_{\mathrm{p}}$ & $3,851,000[\mathrm{~N} / \mathrm{mm}]$ & Pitch spring stiffness \\
$\mathrm{k}_{\mathrm{w}}$ & $0[\mathrm{~N} / \mathrm{mm}]$ & Wrap spring stiffness \\
$\mathrm{c}_{\mathrm{b}}$ & $3390[\mathrm{Ns} / \mathrm{m}]$ & Bounce damping rate \\
$\mathrm{c}_{\mathrm{r}}$ & $459,740[\mathrm{Ns} / \mathrm{m}]$ & Roll damping rate \\
$\mathrm{c}_{\mathrm{p}}$ & $281,780[\mathrm{Ns} / \mathrm{m}]$ & Pitch damping rate \\
$\mathrm{c}_{\mathrm{w}}$ & $500[\mathrm{Ns} / \mathrm{m}]$ & Wrap damping rate \\
$\mathrm{v}_{\mathrm{kb}}$ & $0.2[\mathrm{~m} / \mathrm{s}]$ & Bounce knee velocity \\
$\mathrm{v}_{\mathrm{kro}}$ & $0.2[\mathrm{~m} / \mathrm{s}]$ & Roll knee velocity \\
$\mathrm{v}_{\mathrm{kp}}$ & $0.2[\mathrm{~m} / \mathrm{s}]$ & Pitch knee velocity \\
$\mathrm{v}_{\mathrm{kw}}$ & $0.2[\mathrm{~m} / \mathrm{s}]$ & Wrap knee velocity \\
& $2.5[\mathrm{~Hz}]$ & Bounce natural frequency \\
& $5.9[\mathrm{~Hz}]$ & Roll natural frequency \\
& $3.63[\mathrm{~Hz}]$ & Pitch natural frequency \\
& $14.44[\mathrm{~Hz}]$ & Wrap natural frequency \\
\hline
\end{tabular}

\section{Appendix B. Force/Velocity Graphs for All the Dampers Used}

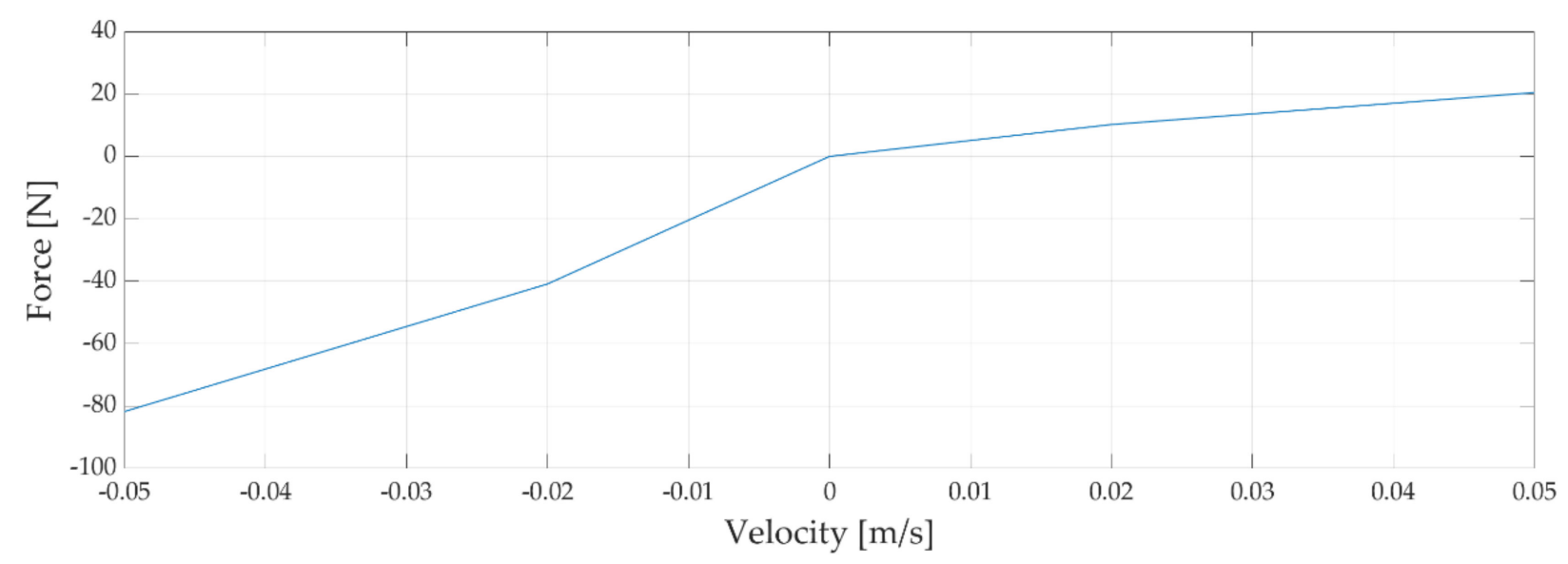

Figure A1. Baseline model front damper Force/Velocity graph. 


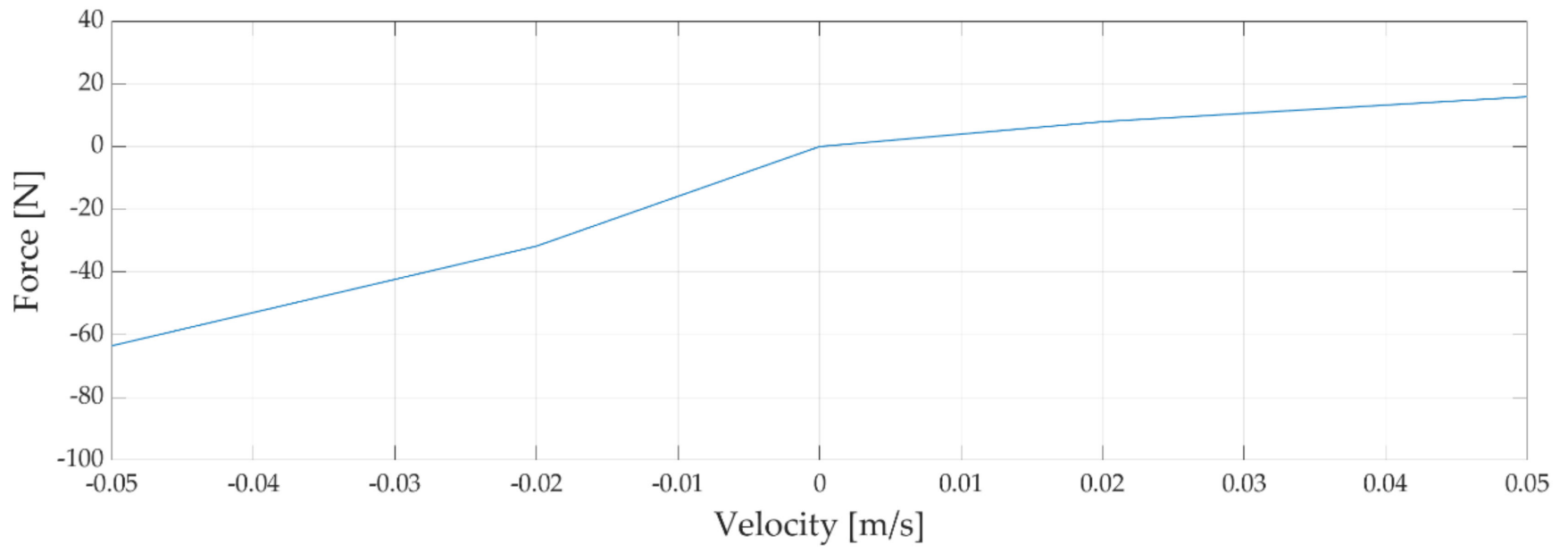

Figure A2. Baseline model rear damper Force/Velocity graph.

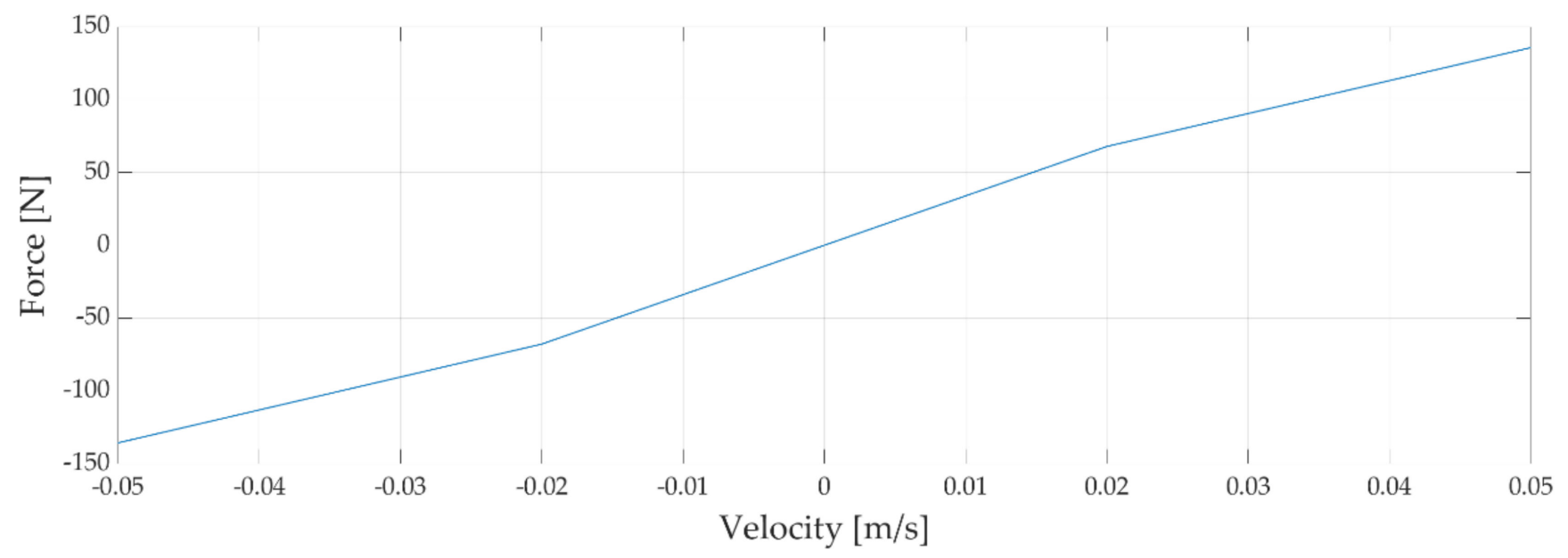

Figure A3. Hydraulically interconnected suspension model bounce damper Force/Velocity graph.

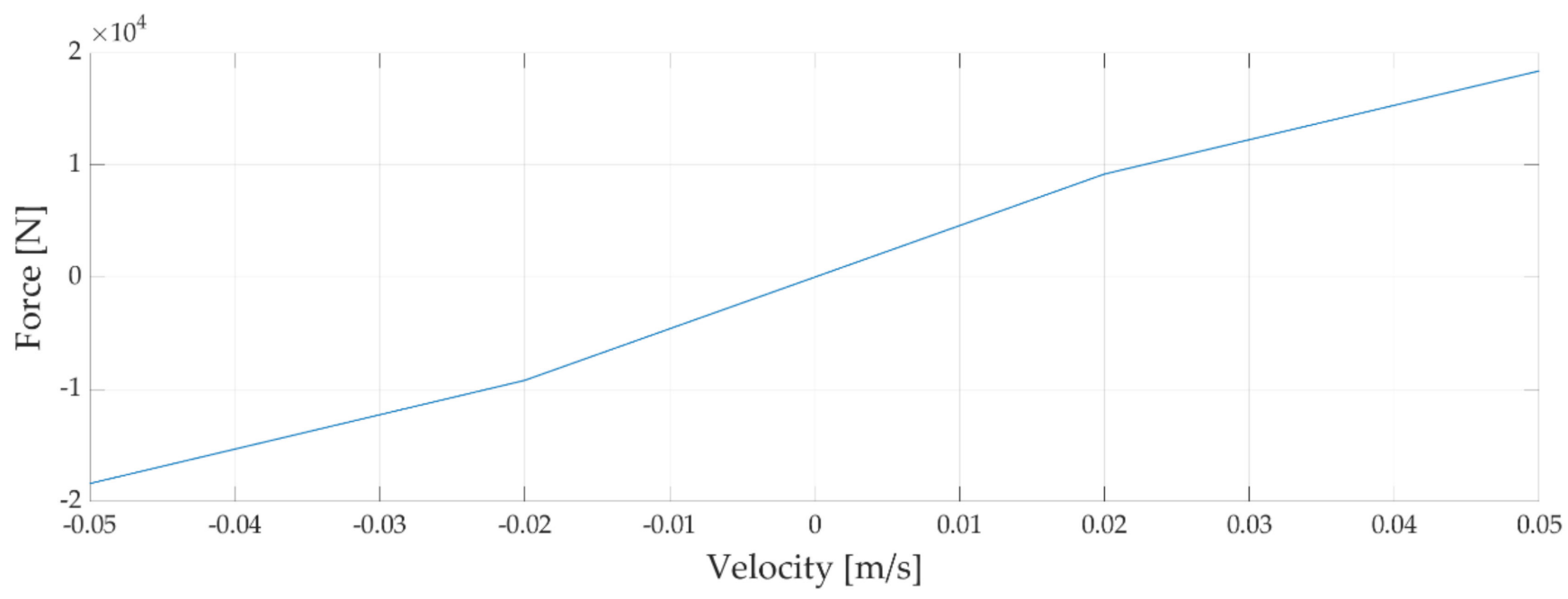

Figure A4. Hydraulically interconnected suspension model roll damper Force/Velocity graph. 


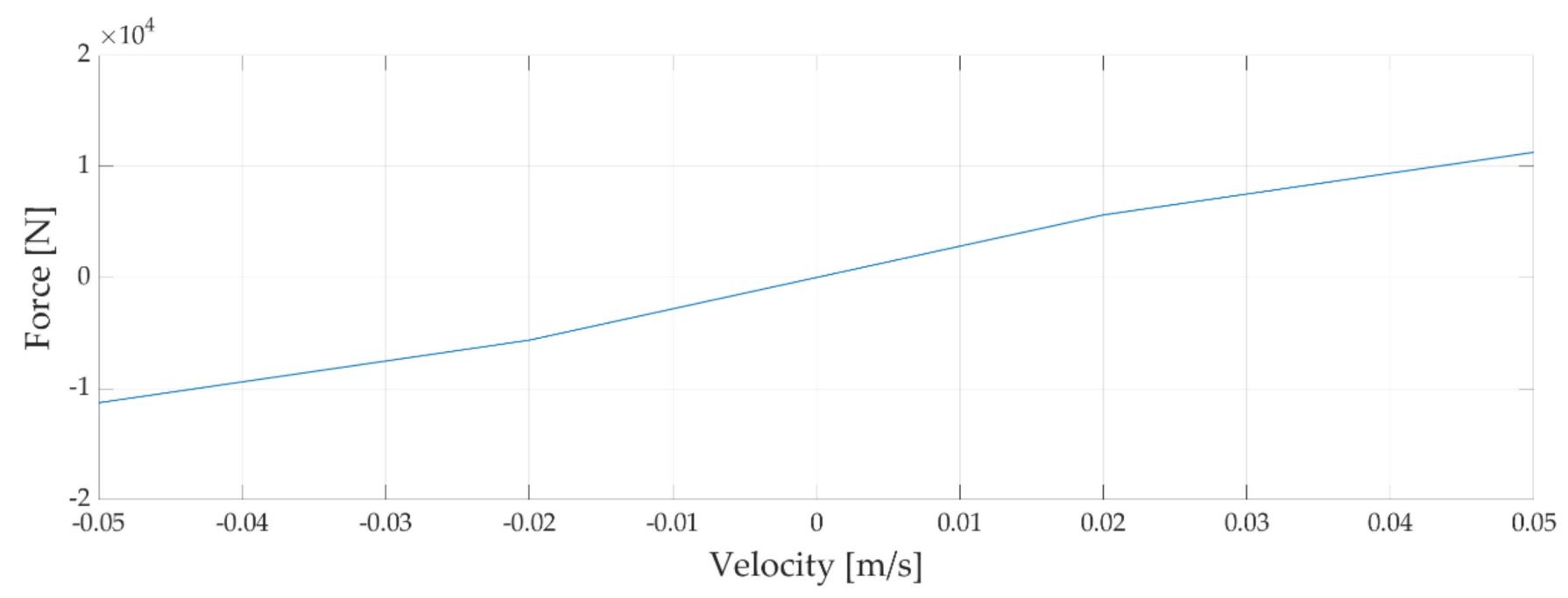

Figure A5. Hydraulically interconnected suspension model pitch damper Force/Velocity graph.

\section{References}

1. Rouelle, C. Advanced Vehicle Dynamics Applied to Race Car Design; OptimumG: Centennial, CO, USA, 2018.

2. Smith, M.C.; Walker, G.W. Interconnected vehicle suspension. Proc. Inst. Mech. Eng. Part D J. Automob. Eng. 2005, 219, 295-307. [CrossRef]

3. Yao, Z. Design and Analysis of an Interconnected Suspension for a Small Off-Road Vehicle. Master's Thesis, University of Windsor, Windsor, ON, Canada, 2016.

4. Berman, R. Optimization of a Three Spring and Damper Suspension. Ph.D. Thesis, University of the Witwatersrand, Johannesburg, South Africa, 2016.

5. Hawley, J.B. Shock Absorber and the Like for Vehicles. U.S. Patent US1647518A, 1 November 1927.

6. Moulton, A.E.; Best, A. Hydragas ${ }^{\circledR}$ Suspension; SAE Technical Paper, No. 790,374; SAE International: New York, NY, USA, 1979.

7. Munday, R.A.; Monk, R. Hydraulic System for A Vehicle. Australia Patent AU2003900894A0, 13 March 2003.

8. Glover, A.R.; Burnham, P.A. A Damper Unit for A Vehicle Suspension System and A Vehicle Including Such A Damper Unit. UK Patent GB2474030A, 2009.

9. Smith, M.; Hoult, W.; Brezas, P. McLaren Earns Its Ph. D. in Handling: McLaren Automotive and the University of Cambridge Collaborate on a No-Compromise Semi-Active Suspension for the 720 S Supercar; Automotive Engineering; SAE International: New York, NY, USA, 2018; pp. 34-35.

10. Collins, S. F1 2014 Explained: What is FRICS? Racecar Engineering. Available online: https:/ /www.racecar-engineering.com/techexplained/f1-2014-explained-what-is-frics (accessed on 5 May 2021).

11. Jazar, R.N. Vehicle Dynamics: Theory and Application, 2nd ed.; Springer: Cham, Switzerland, 2017; Chapter 13.

12. Giariffa, M.; Brisson, S. Tech Tip: Spring E Dampers, Episode Four, a New Understanding; OptimumG: Centennial, CO, USA, 2017.

13. Rijk, S.V. Optimization of the Damper Settings of the URE05e. Master's Thesis, Eindhoven University of Technology, Eindhoven, The Netherlands, 2010.

14. Milliken, W.F.; Milliken, D.L. Race Car Vehicle Dynamics, 2nd ed.; Society of Automotive Engineers: Warrendale, PA, USA, 1995; Chapter 22.

15. Dixon, J.C. The Shock Absorber Handbook, 2nd ed.; John Wiley \& Sons: Hoboken, NJ, USA; Professional Engineering Publishing: Chichester, UK, 2007.

16. MATLAB Version 9.8.0 (R2020a); The MathWorks Inc.: Natick, MA, USA, 2010.

17. OptimumLap Version 1.4; OptimumG: Centennial, CO, USA, 2020.

18. Patton, C. Development of Vehicle Dynamics Tools for Motorsports. Ph.D. Thesis, Oregon State University, Corvallis, OR, USA, 2013.

19. Agostinacchio, M.; Ciampa, D.; Olita, S. The vibrations induced by surface irregularities in road pavements-A Matlab ${ }^{\circledR}$ approach. Eur. Transp. Res. Rev. 2014, 6, 267-275. [CrossRef]

20. Durfee, W.; Sun, Z.; Van de Ven, J. Fluid Power System Dynamics; Center for Compact and Efficient Fluid Power: Minneapolis, MN, USA, 2009. 